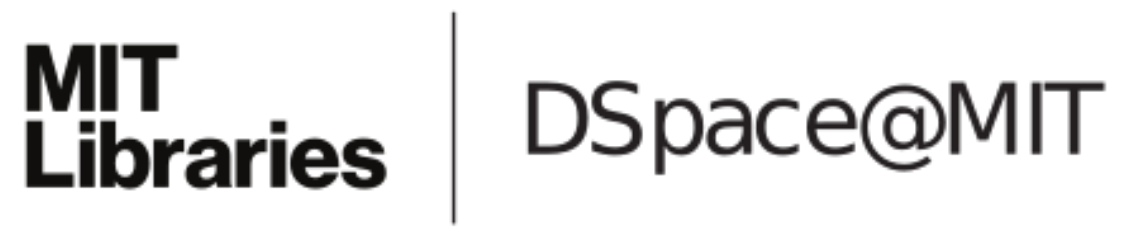

\author{
MIT Open Access Articles
}

\begin{abstract}
Network-Strengthened Ti-6Al-4V/(TiC+TiB) Composites:
Powder Metallurgy Processing and Enhanced

Tensile Properties at Elevated Temperatures
\end{abstract}

The MIT Faculty has made this article openly available. Please share how this access benefits you. Your story matters.

As Published: https://doi.org/10.1007/s11661-019-05244-7

Publisher: Springer US

Persistent URL: https://hdl.handle.net/1721.1/131895

Version: Author's final manuscript: final author's manuscript post peer review, without publisher's formatting or copy editing

Terms of Use: Article is made available in accordance with the publisher's policy and may be subject to US copyright law. Please refer to the publisher's site for terms of use. 


\section{Network-Strengthened Ti-6Al-4V/(TiC+TiB) Composites: Pow- der Metallurgy Processing and Enhanced Tensile Properties at Elevated Temperatures}

Cite this article as: Shaolou Wei, Lujun Huang, Xinting Li, Yang Jiao, Wei Ren and Lin Geng, Network-Strengthened Ti-6Al-4V/(TiC+TiB) Composites: Powder Metallurgy Processing and Enhanced Tensile Properties at Elevated Temperatures, Metallurgical and Materials Transactions A https://doi.org/10.1007/s11661-019-05244-7

This Author Accepted Manuscript is a PDF file of an unedited peer-reviewed manuscript that has been accepted for publication but has not been copyedited or corrected. The official version of record that is published in the journal is kept up to date and so may therefore differ from this version.

Terms of use and reuse: academic research for non-commercial purposes, see here for full terms. https://www.springer.com/aam-terms-v1 
Network strengthened Ti-6Al-4V/(TiC+TiB) composites:

powder metallurgy processing and enhanced tensile properties at elevated temperatures

\section{$\underline{\text { List of author and affiliations: }}$}

\section{Shaolou Wei, lead author}

School of Materials Science and Engineering, Harbin Institute of Technology, Harbin 150001, P.R. China Currently with: Department of Materials Science and Engineering, Massachusetts Institute of Technology, Cambridge, MA02139, United States of America

E-mail: slwei@mit.edu

\section{Lujun Huang, corresponding author 1, project coordinator}

School of Materials Science and Engineering, Harbin Institute of Technology, Harbin 150001, P.R. China E-mail: huanglujun@hit.edu.cn

Fax: +86-451-86413921

\section{Xinting Li, contributing author}

School of Materials Science and Engineering, Harbin Institute of Technology, Harbin 150001, P.R. China E-mail: lixinting1990@163.com

\section{Yang Jiao, contributing author}

School of Materials Science and Engineering, Harbin Institute of Technology, Harbin 150001, P.R. China E-mail: jiaoyanger@126.com

\section{Wei Ren, contributing author}

School of Materials Science and Engineering, Harbin Institute of Technology, Harbin 150001, P.R. China E-mail:wren@stu.hit.edu.cn 


\section{Lin Geng, corresponding author 2, research group leader}

School of Materials Science and Engineering, Harbin Institute of Technology, Harbin 150001, P.R. China E-mail: genglin@ @it.edu.cn

Fax: +86-451-86413907

Network strengthened Ti-6Al-4V/(TiC+TiB) composites:

powder metallurgy processing and enhanced tensile properties at elevated temperatures

Shaolou Wei ${ }^{\dagger}$, Lujun Huang*, Xinting Li, Yang Jiao, Wei Ren, and Lin Geng* 


\section{Abstract:}

Starting with graphite, $\mathrm{TiB}_{2}$, and $\mathrm{Ti}-6 \mathrm{Al}-4 \mathrm{~V}$ powders, the present work demonstrated that hybrid $(\mathrm{TiC}+\mathrm{TiB})$ network strengthened Ti-6Al-4V-based composites can be fabricated via an integrated low-energy ball-milling and reaction hot pressing sintering technique. With the aids of phase equilibrium and powder densification kinetic calculations, the corresponded sintering parameters were optimized and tunable network microstructures were subsequently achieved. Tensile properties for these composites were examined at elevated temperatures of 500, 550,600 , and $650{ }^{\circ} \mathrm{C}$, the results of which indicated that the $50 \mu \mathrm{m}$ network configuration with 5 vol. $\%$ reinforcer content led to the most enhanced tensile strength compared to both Ti-6Al-4V alloys and solely TiB reinforced Ti-6Al-4V composites. The underlying strengthening mechanisms were mainly ascribed to: carbon interstitial dissolution, reinforcer-assisted grain refinement, and extensive dispersoids. It was recognized from fractographic analyses that matrix/reinforce interface contributed to the main crack propagation source at temperatures below 550 ${ }^{\circ} \mathrm{C}$, leading to brittle-like fracture along the network boundary; however, once testing temperatures rose above 600 ${ }^{\circ} \mathrm{C}$, matrix tearing and reinforcer cut-through mechanisms took place, giving rise to ductile fracture. Based on the experimental observations and theoretical calculations, future perspectives regarding the processing and microstructural manipulation for advanced high-temperature titanium matrix composites were also discussed.

Keywords: powder metallurgy; titanium matrix composites; high-temperature mechanical properties; microstructural evolution

*Corresponding authors: L.J. Huang (huanglujun@ hit.edu.cn); L. Geng (genglin@ hit.edu.cn)

$\dagger$ Present address: Department of Materials Science and Engineering, Massachusetts Institute of Technology, Cambridge, MA 02139, U.S.A.

\section{Introduction}

Stimulated by the rapid development in aerospace engineering, there has been growing effort in investigating advanced metallic-based materials with excellent specific mechanical properties and outstanding physicochemical 
stability at elevated temperatures ${ }^{[1]}$. With regard to this, Ti-based alloys have attracted broad attention owing to their unique combination of low density, superior strength, and desirable chemical corrosion resistance ${ }^{[2-4]}$. Fig. 1 summaries the specific strength with respect to service temperature for conventional engineering materials. In the temperature range from ambient value up to $400{ }^{\circ} \mathrm{C}$, Ti-based alloys exhibit more favorable specific strength compared to Al-based alloys, heat-resistant stainless steels, and poly-crystalline Ni-based superalloys. Nonetheless, their specific strengths display a dramatic decreasing trend as the service temperature approaches $600{ }^{\circ} \mathrm{C}$, which largely hinders their potential applications. Moreover, Ti-based alloys often possess strong oxidation propensity at elevated temperatures which further expedites their degradation due to the formation of porous $\mathrm{TiO}_{2}$ oxide scale or the embrittlement problem induced by oxygen-rich $\alpha$-phase ${ }^{[5,6]}$. In a sense to improve these shortcomings, appreciable investigations have been accomplished toward compositional optimization ${ }^{[7,8]}$, microstructural modulation ${ }^{[9-11]}$, and surface modification ${ }^{[12-14]}$. Although these strategies have enabled property enhancement of Ti-based alloys, challenges still exist from a processing perspective, since the aforementioned approaches either require the addition of high-cost alloying elements or involve precise control of thermo-mechanical treatment conditions.

Over the past decades, the development of Ti-matrix composites (TMCs) has paved a novel cost-effective way for the improvement of high-temperature performances ${ }^{[15]}$. By incorporating commercial engineering ceramic reinforcers such as $\mathrm{SiC}, \mathrm{TiB}$, and $\mathrm{TiC}$, a variety of TMCs have been successfully developed and examined to achieve desirable properties at both ambient and elevated temperatures ${ }^{[16-18]}$. Based on the characteristics of reinforcers, the development of TMCs can be categorized into three stages ${ }^{[15,19]}$ : (1) continuously reinforced TMCs with homogenously distributed reinforcers; (2) discontinuously reinforced TMCs with homogenously distributed reinforcers; and (3) discontinuously reinforced TMCs with inhomogenously distributed reinforcers. In fact, decades of effort has demonstrated that while continuous fiber reinforced TMCs (such as Ti/SiC composites) exhibit 
considerable improvement in high-temperature durability such as creep resistance, the strong mechanically anisotropic effect together with the complexity in processing (mostly diffusion bonding technique) dramatically decrease their engineering application potential ${ }^{[20-22]}$ In recent years, comparatively more attention has been directed into the investigation of the latter two types of TMCs ${ }^{[23]}$.

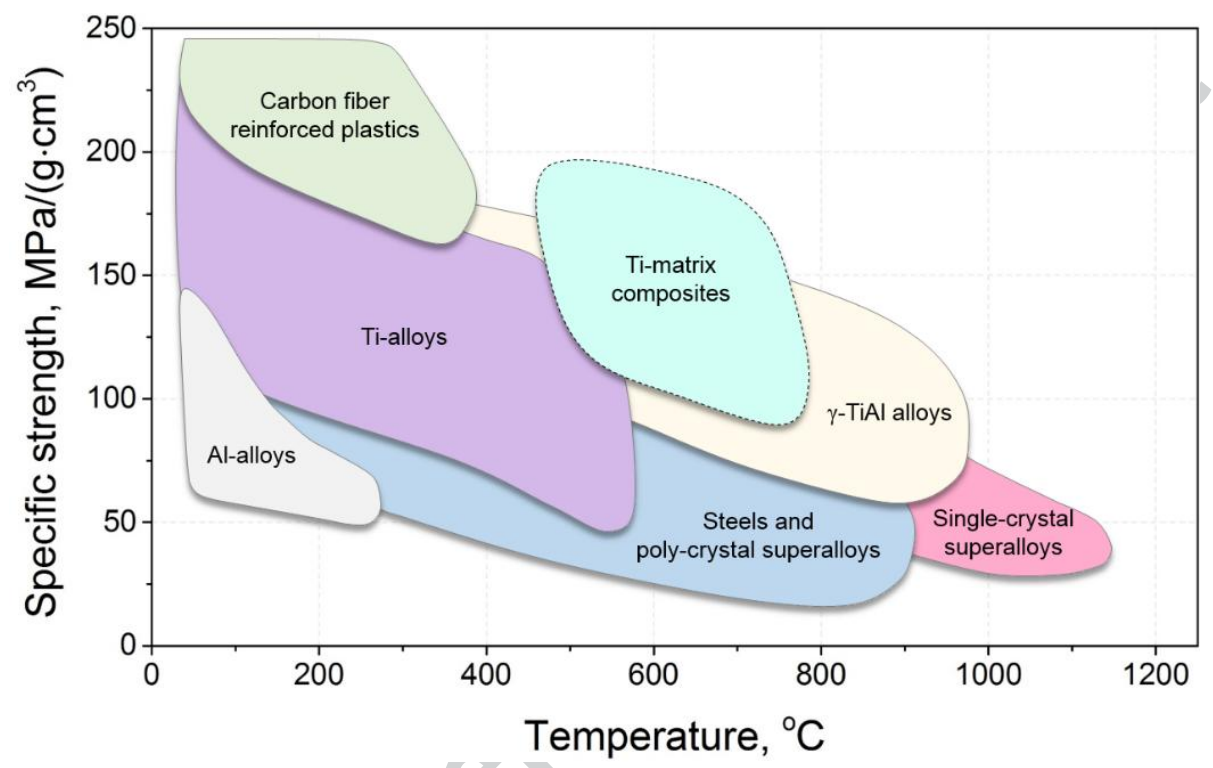

Figure 1 | Specific strength versus service temperature for typical structural materials (data excerpted from ref. $\left.{ }^{[24,25]}\right)$.

In order to achieve homogenous reinforcer distribution in TMCs, a great amount of work has been accomplished by utilizing conventional melting-casting technique. $\mathrm{Li}$ et al. ${ }^{[26]}$ reported that $\mathrm{Ti} /\left(\mathrm{TiB}+\mathrm{La}_{2} \mathrm{O}_{3}\right)$ composites processed by vacuum arc melting exhibited even better creep resistance compared to IMI 834 high-temperature titanium alloys. By employing an investment casting approach, Choi et al. ${ }^{[27]}$ fabricated Ti/(TiB+TiC) composites where favorable wear resistance was consequently achieved. More recently, bimodal-sized near $\alpha-\mathrm{Ti} /\left(\mathrm{TiB}+\mathrm{Y}_{2} \mathrm{O}_{3}\right)$ composites synthesized via in-situ casting method were also found to exhibit enhanced compressive properties ${ }^{[28]}$. Although TMCs produced by common melting and casting routes have shown great potential in terms of property enhancement, their limitations still remain in three respects: (1) the existence of intrinsic casting imperfections; (2) 
the necessity of proceeding thermo-mechanical treatment; and more importantly (3) the deficiency in reinforcer distribution tunability. In fact, TMCs with homogenous reinforcer distribution often inevitably suffer from particle (or whisker) clustering, which dramatically destructs their damage tolerance or even induces severe local embrittlement problem at ambient temperature.

To this end, Huang et al. ${ }^{[29]}$ re-examined the TMCs design principles by tuning network distributed TiB in Ti-6Al-4V matrix through integrated ball-milling and reaction hot pressing sintering approach. They demonstrated that this sort of composites with inhomogeneous reinforcer distribution exhibited significant improvement in tensile strength without sacrificing too much ductility. Furthermore, it has also been recognized that powder metallurgy approach not only avoids the inherent casting imperfections but also enables a large degree of freedom for manipulating reinforcer distribution in terms of microstructural design ${ }^{[15]}$. Following this strategy, various TMCs with inhomogeneous reinforcer distribution has been successfully developed. In particular, Huang et al. showed that by optimizing the $\mathrm{TiB}$ content, the Ti-6Al-4V/TiB composites achieved more desirable high-temperature tensile properties compared to Ti-6Al-4V alloys ${ }^{[15]}$. A more recent investigation accomplished by Wang et al. ${ }^{[30]}$ also confirmed the beneficial effect of inhomogeneous TiB network on creep resistance. Despite their improved high-temperature mechanical performances, the Ti-6Al-4V/TiB composites still suffered from network boundary softening issues, in addition, they demonstrated deteriorated oxidation resistance due to the evaporation of boron oxides ${ }^{[5,31]}$.

With superior hardness and outstanding physicochemical stability at elevated temperatures, TiC has been considered as another type of promising reinforcer to resolve these challenges ${ }^{[15,19,23]}$, and the most common processing technique employed to introduce both $\mathrm{TiC}$ and $\mathrm{TiB}$ into $\mathrm{Ti}-6 \mathrm{Al}-4 \mathrm{~V}$ alloys is melting and casting: by introducing both $\mathrm{TiC}$ and $\mathrm{TiB}$ reinforcers into the Ti-6Al-4V alloys through a conventional vacuum induction (C) 2019 The Minerals, Metals \& Materials Society and ASM International. 
melting and hot rolling procedure, Rastegari et al. ${ }^{[32]}$ reported that a desirable strength-ductility combination can be achieved at ambient temperature: the composites demonstrated an ultimate tensile strength of $1240 \mathrm{MPa}$ while preserving a fracture elongation of $9 \%$. Yang et al. ${ }^{[33]}$ examined the dry sliding wear behavior of the Ti-6Al-4V/(TiC+TiB) composites synthesized through consumable vacuum arc melting and hot forging. They revealed that the enhanced wear resistance benefited from the dispersoid strengthening and effective load transfer brought about by the $(\mathrm{TiC}+\mathrm{TiB})$ reinforcers. While these investigations have certainly promoted the mechanical performances of Ti-6Al-4V alloys, the inevitable particle/whisker clustering problem originated from casting procedure still seriously hinders the composites' damage tolerance capability ${ }^{[34]}$. Moreover, comparatively less attention has been paid to the high-temperature mechanical performances for this type of composites. The exploration of cost-effective processing route, the in-depth understanding of the corresponded microstructural evolution mechanisms, and the assessment of their properties at elevated temperatures are still in lack.

The present work aims to peruse more enhanced performances of Ti-6Al-4V alloys at elevated temperatures by constructing a hybrid ( $\mathrm{TiC}+\mathrm{TiB})$ network reinforcer configuration. It is demonstrated that (TiC+TiB) hybridly reinforced Ti-6Al-4V-based composites can be fabricated by utilizing powder metallurgy technique. With the aid of a two-body sintering model, the sintering parameters have been successfully optimized and tunable network microstructures were consequently achieved. The uniaxial tensile properties for the composites with three different network sizes were examined at elevated temperatures of $500,550,600$, and $650{ }^{\circ} \mathrm{C}$. It is recognized that the configuration of $50 \mu \mathrm{m}$ network size and 5 vol. \% hybrid reinforcers addition leads to the most significant property enhancement compared to both Ti-6Al-4V alloy and solely TiB reinforced composite.

\section{Experimental procedure}




\subsection{Materials fabrication}

As illustrated in Fig. 2, raw materials including large spherical Ti-6Al-4V powders (chemical compositions were summarized in $\mathrm{Tab} .1$ ), fine graphite, and $\mathrm{TiB}_{2}$ powders were employed for composites fabrication. To manipulate the hybrid network configuration, Ti-6Al-4V powders with average diameters of 50,100, and $140 \mu \mathrm{m}$ were chosen for the present investigation (total reinforcer fraction: 5 vol. \%). These powders were subjected to low-energy ball milling for $5 \mathrm{~h}$ at a speed of $150 \mathrm{rpm}$ under high-purity argon protection (ball to powders ratio was kept at 5:1). Fig. 2 (d) presents the powder morphology after being ball-milled. It is evident that $\mathrm{TiB}_{2}$ and graphite uniformly adhered onto the surface of Ti-6Al-4V powders and the mixed powders preserved their original spherical geometry, indicating no severe plastic deformation was induced during the ball milling procedure. The mixed powders were subsequently sintered under an external pressure of $25 \mathrm{MPa}$ at an optimized temperature of $1200{ }^{\circ} \mathrm{C}$ for $50 \mathrm{~min}$ (see section 3.1), during which the vacuum level was kept below $10^{-4} \mathrm{~Pa}$.
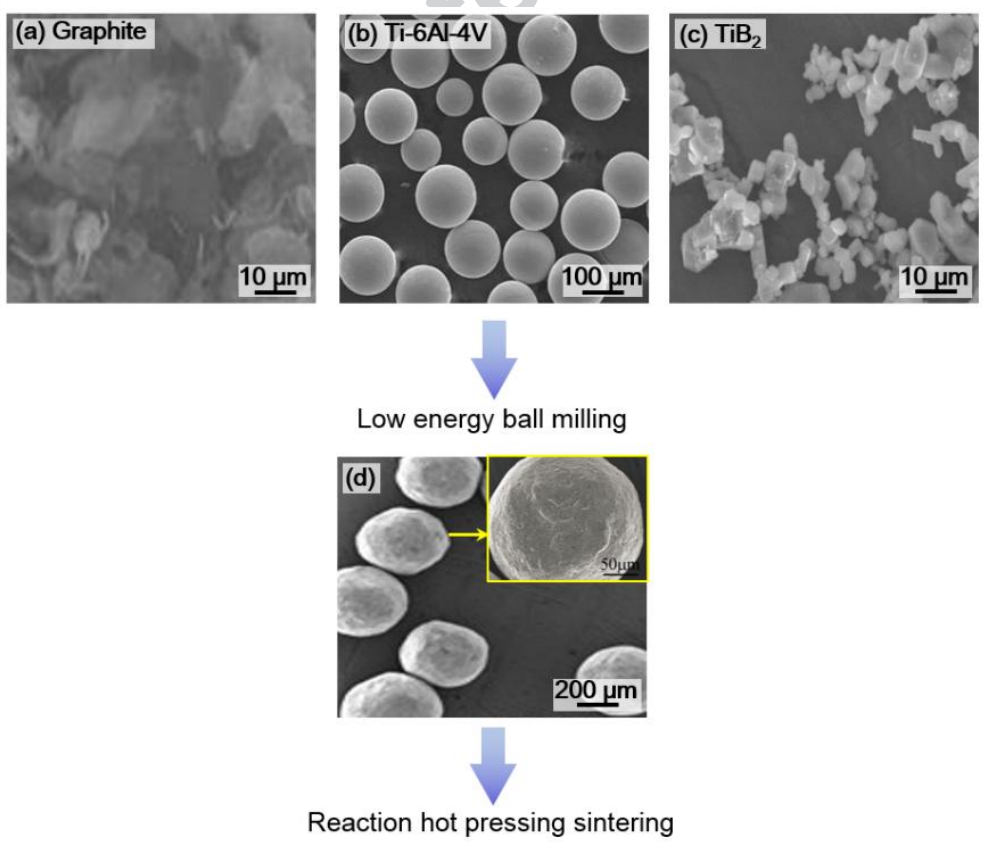

Figure 2 | SEM micrographs for powder morphology: (a) graphite; (b) Ti-6Al-4V; (c) TiB ${ }_{2}$; (d) mixed powder after 5 $h$ low-energy ball-milling (inset: higher magnification image of powder surface). 


\begin{tabular}{llllllllll}
\hline Element & $\mathrm{Ti}$ & $\mathrm{Al}$ & $\mathrm{V}$ & $\mathrm{Fe}$ & $\mathrm{O}$ & $\mathrm{Si}$ & $\mathrm{C}$ & $\mathrm{N}$ & $\mathrm{H}$ \\
Wt.\% & 89.228 & 6.420 & 4.120 & 0.180 & 0.120 & 0.024 & 0.013 & 0.011 & 0.004 \\
\hline
\end{tabular}

\subsection{Mechanical testing and microstructural characterization}

After being furnace cooled down to ambient temperature, the bulk composites with $\sim 60 \mathrm{~mm}$ diameter were sectioned into dog-bone shapes (gauge geometry $12 \times 3 \times 1.8 \mathrm{~mm}^{3}$ ) via electrical discharge machining (EDM) technique. The tensile specimens were mechanically grinded up to 1200 \# SiC polishing papers and polished by $\mathrm{Cr}_{2} \mathrm{O}_{3}$ suspension before being ultrasonically cleaned in acetone bath. Uniaxial tensile experiment was conducted at elevated temperatures of $500,550,600$, and $650{ }^{\circ} \mathrm{C}$ under a loading rate of $0.5 \mathrm{~mm} / \mathrm{min}$ on an INSTRON-1186 mechanical testing facility. All specimens were kept for $5 \mathrm{~min}$ before loading so as to ensure uniform temperature distribution, and were water-quenched right after fracture to preserve the high-temperature microstructures. At least three specimens were tested at each condition in order to secure reproducibility. Phase constitution of the composites was analyzed by a Panalytical Empyrean X-ray diffractometer (XRD) with the scan angle range of 20-90 degree in the step of 0.02 degree. Microstructural characteristics of the composites before and after testing were investigated via a Zeiss SUPRA 55 SAPPHIR scanning electron microscope (SEM) equipped with an INCA 300 energy dispersive spectrometer (EDS). Grain size assessment for the composites was carried out via the particle analysis function in an Image-J open access software using the micrographs taken from an OLYMPUS PMG-3 optical microscope (OM). A TALOS 200 transmission electron microscope (TEM) was employed for interfacial characterization and TEM samples were prepared through ion beam milling.

\section{Results}

\subsection{Thermodynamic and kinetic considerations}


The introduction of both $\mathrm{TiC}$ and $\mathrm{TiB}$ reinforcers relies on two spontaneous in-situ chemical reactions amongst

$\mathrm{TiB}_{2}$ and graphite with Ti at elevated temperatures:

$$
\begin{aligned}
& \mathrm{C}(\text { graphite, } \mathrm{s})+\mathrm{Ti}(\beta, \mathrm{s}) \rightarrow \mathrm{TiC} \text { (particle) } \\
& \mathrm{TiB}_{2}(\mathrm{~s})+\mathrm{Ti}(\beta, \mathrm{s}) \rightarrow 2 \mathrm{TiB} \text { (whisker) }
\end{aligned}
$$

To better elucidate the equilibrium phase constitution in such composite system, theoretical prediction on phase stability with respect to temperature was carried out through the JMatPro thermodynamic calculation platform, where the composition of the Ti-6Al-4V/(2.5 vol. \% $\mathrm{TiC}+2.5$ vol. \% $\mathrm{TiB})$ composites was converted into weight percentage: Ti-5.68Al-3.78V-0.55C-0.47B. Calculation results illustrated in Fig. 3 (a) indicate that the $\alpha$-to- $\beta$ transition takes place at about $800{ }^{\circ} \mathrm{C}$ and completes at $1080{ }^{\circ} \mathrm{C}$. Within the calculation temperature range, $\mathrm{TiB}$ phase demonstrates superior stability to $\mathrm{TiC}$ phase, the latter, on the other hand, exhibits rather complicated equilibrium fraction in various temperature ranges. It is recognized from Fig. 3 (a) that TiC-phase fraction shows the following four-stage characteristics with respect to increasing temperature: (1) monotonic decrease (ambient temperature to $\left.800{ }^{\circ} \mathrm{C}\right)$; (2) near-zero fraction $\left(800-1000{ }^{\circ} \mathrm{C}\right)$; (3) monotonic increase $\left(1000-1080{ }^{\circ} \mathrm{C}\right)$; and (4) again monotonic decrease (above $1080{ }^{\circ} \mathrm{C}$ ). The existence of regimes (1), (2), and (4) is ascribed to the increase of carbon solubility within the dominant phase as temperature rises ( $\alpha$ phase for (1) and (2); $\beta$ phase for (4)). While the monotonic increase regime (3) can be understood from the net effect of allotropic transition and difference in C solubility between $\alpha$ and $\beta$ phases: as revealed in Fig. 3 (a), the $\alpha$-to- $\beta$ transition is activated at $800{ }^{\circ} \mathrm{C}$, and as temperature increases to around $1000{ }^{\circ} \mathrm{C}, \beta$-phase starts to become the major phase within the composite system (transition completes at $1080{ }^{\circ} \mathrm{C}$ ). Since $\mathrm{C}$ demonstrates comparatively lower solubility in the body-centered cubic structured $\beta$-phase than the hexagonal closed packed structured $\alpha$-phase, the excess $C$ content begins to precipitate out in the form of $\mathrm{TiC}$ and thereby gives rise to the increasing $\mathrm{TiC}$ fraction as predicted by the calculation. These results suggest that the reaction hot pressing sintering procedure should be carried out at temperatures higher than $1000{ }^{\circ} \mathrm{C}$ but no more than $1300{ }^{\circ} \mathrm{C}$. 
(a) Equilibrium phase constitution

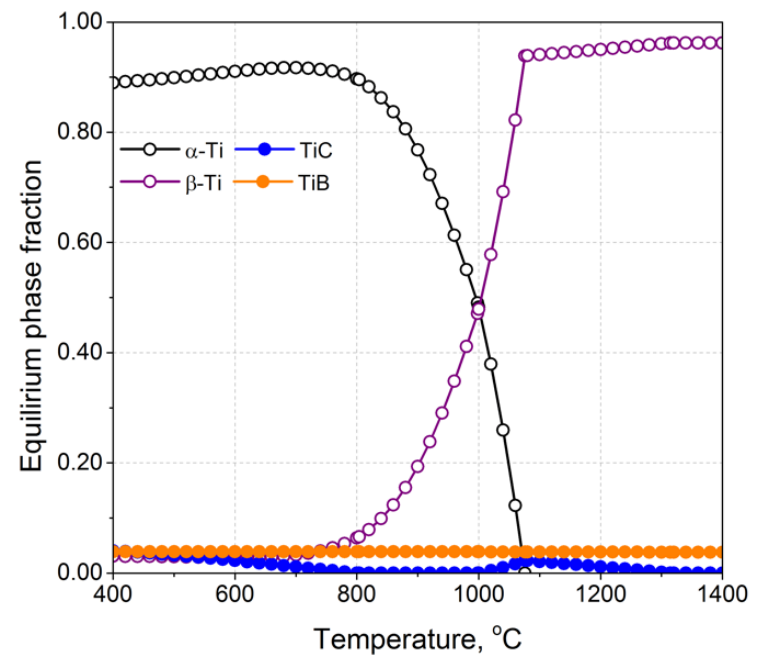

(b) Densification kinetics at $p=25 \mathrm{MPa}$

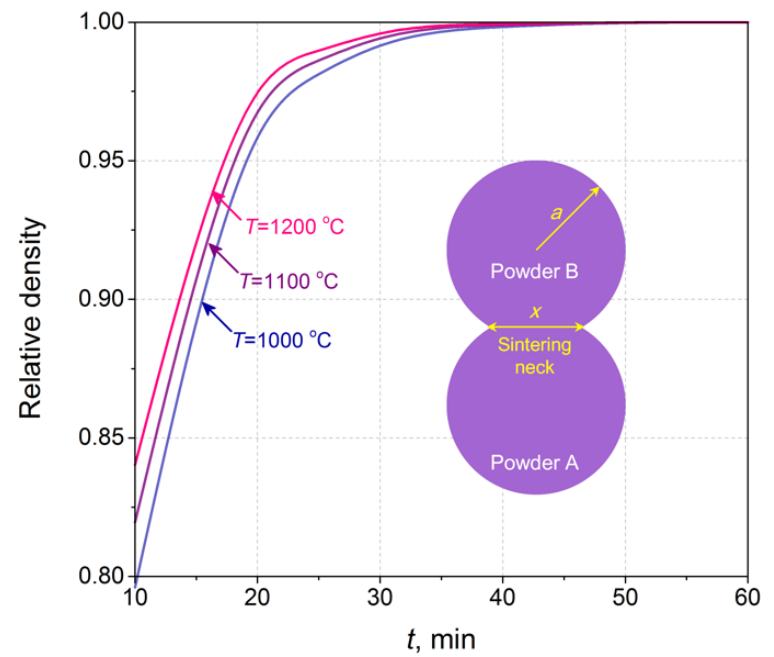

Figure 3 | Thermodynamic and kinetic calculation results: (a) equilibrium phase constitution with respect to temperature; (b) relative density change versus time at an applied pressure of $25 \mathrm{MPa}$.

To further understand the densification kinetics and thereby optimize the sintering parameters, a two-body reaction sintering model was employed to conduct theoretical assessment. It is assumed in the present calculation that: (1) composite powders possess perfect spherical geometry; (2) bulk diffusion is the dominant factor for densification; and (3) no selective densification exists during the whole procedure. According to Kang ${ }^{[35]}$, the effective pressure $p^{e f f}$. during sintering can be expressed as a piecewise function $p^{a p p l}$ of applied load at a transient relatisve density $\rho_{r}$ :

$$
p^{e f f .}=\left\{\begin{array}{c}
p^{a p p l} \cdot 4 a^{2} / \pi x^{2}\left(\rho_{r}<0.9\right) \\
p^{a p p l .} / \rho_{r}\left(\rho_{r}>0.9\right)
\end{array}\right.
$$

Where as schematically shown in the inset of Fig. 3 (b), $a$ and $x$ denote the radii of the powders and dimension of sintering neck. The densification rate can be expressed as Eq. (3) at temperatures where the applied pressure is significantly higher than the yielding strength of the powders ${ }^{[35]}$ :

$$
\frac{d \rho_{r}}{d t}=\frac{3 p^{a p p l .}}{4 \eta}\left(1-\rho_{r}\right)
$$

Where the viscosity of solid at elevated temperatures $\eta$ can be determined from the Norton equation ${ }^{[36]}$ : 


$$
\eta=\frac{k_{B} T G_{0}^{2}}{10 D_{V} V_{0}}
$$

Where $k_{B}, T, G_{0}, D_{V}$, and $V_{0}$ denote the Boltzmann constant, absolute temperature, initial grain size, bulk diffusivity, and atomic size. Parameters of Ti-6Al-4V alloy (Tab. 2) were adopted as a first-order approximation in the present calculation, and the corresponded applied pressure value was set as $25 \mathrm{MPa}$ (maximum value in the present presser). By combining Eqs. (3)-(5), the calculated relative density change with respect to sintering time is shown in Fig. 3 (b). At all three temperatures $\left(1000,1100\right.$, and $\left.1200^{\circ} \mathrm{C}\right)$, relative density exhibits a dramatic increase in the first $30 \mathrm{~min}$, and subsequently decreases with proceeding sintering period. After $50 \mathrm{~min}$, the relative density under these three conditions all exceed 0.999 , which can be regarded as fully densified. The combination of both phase stability thermodynamic and sintering kinetics suggest such reaction hot pressing sintering process should be conducted at temperatures higher than $1000{ }^{\circ} \mathrm{C}$, for at least 60 min under an applied pressure of $25 \mathrm{MPa}$.

Table 2 | Physical parameters adopted for densification kinetics calculation

\begin{tabular}{cccc}
\hline Parameter & Value & Unit & Reference \\
\hline$k_{B}$ & $1.38 \times 10^{-23}$ & $\mathrm{~J} / \mathrm{K}$ & {$[36]$} \\
$G_{0}$ & $10^{-10}$ & $\mathrm{~m}$ & This work \\
$D_{V}$ & $10^{-9}-10^{-10}$ & $\mathrm{~m}^{2} / \mathrm{s}$ & {$[36]$} \\
$V_{0}$ & $10^{-36}$ & $\mathrm{~m}^{3}$ & \\
$a$ & $5 \times 10^{-5}$ & $\mathrm{~m}$ & This work \\
$x$ & $10^{-5}$ & $\mathrm{~m}$ & This work
\end{tabular}

\subsection{Microstructural characteristics}

Following the theoretical predictions demonstrated above, Ti-6Al-4V/(TiC+TiB) composites with $50 \mu \mathrm{m}$ network configuration were fabricated in a sense to determine the optimal processing temperature. Fig. 4 display the SEM micrographs for the composites fabricated at $1000,1100,1200{ }^{\circ} \mathrm{C}$. In addition to the relatively high density of 
pores and unreacted regimes, only tiny needle-shaped TiB whiskers form in the network structure for the composite sintered at $1000{ }^{\circ} \mathrm{C}$. (Figs. 4 (a1) and (a2)), and similar characteristics also appear within composite fabricated at $1100{ }^{\circ} \mathrm{C}$ (Figs. 4 (b1) and (b2)). Such discrepancies between actual microstructural morphologies and theoretical predictions shown in Fig. 3 (b) indicated that the formation of TiC and TiB reinforcers along the boundary suppress the densification kinetics, suggesting higher temperature should be applied to achieve fully densified microstructure. At $1200{ }^{\circ} \mathrm{C}$, the composites demonstrate perfect microscopic densification where no pores or reinforcer pile-ups regimes were formed (reacted regime exhibit a width of $\sim 2.5 \mu \mathrm{m}$ ), implying that sintering at $1200{ }^{\circ} \mathrm{C}$ under $25 \mathrm{MPa}$ applied pressure for $60 \mathrm{~min}$ are the optimal processing conditions for the present Ti-6Al-4V/(TiC+TiB) composites.
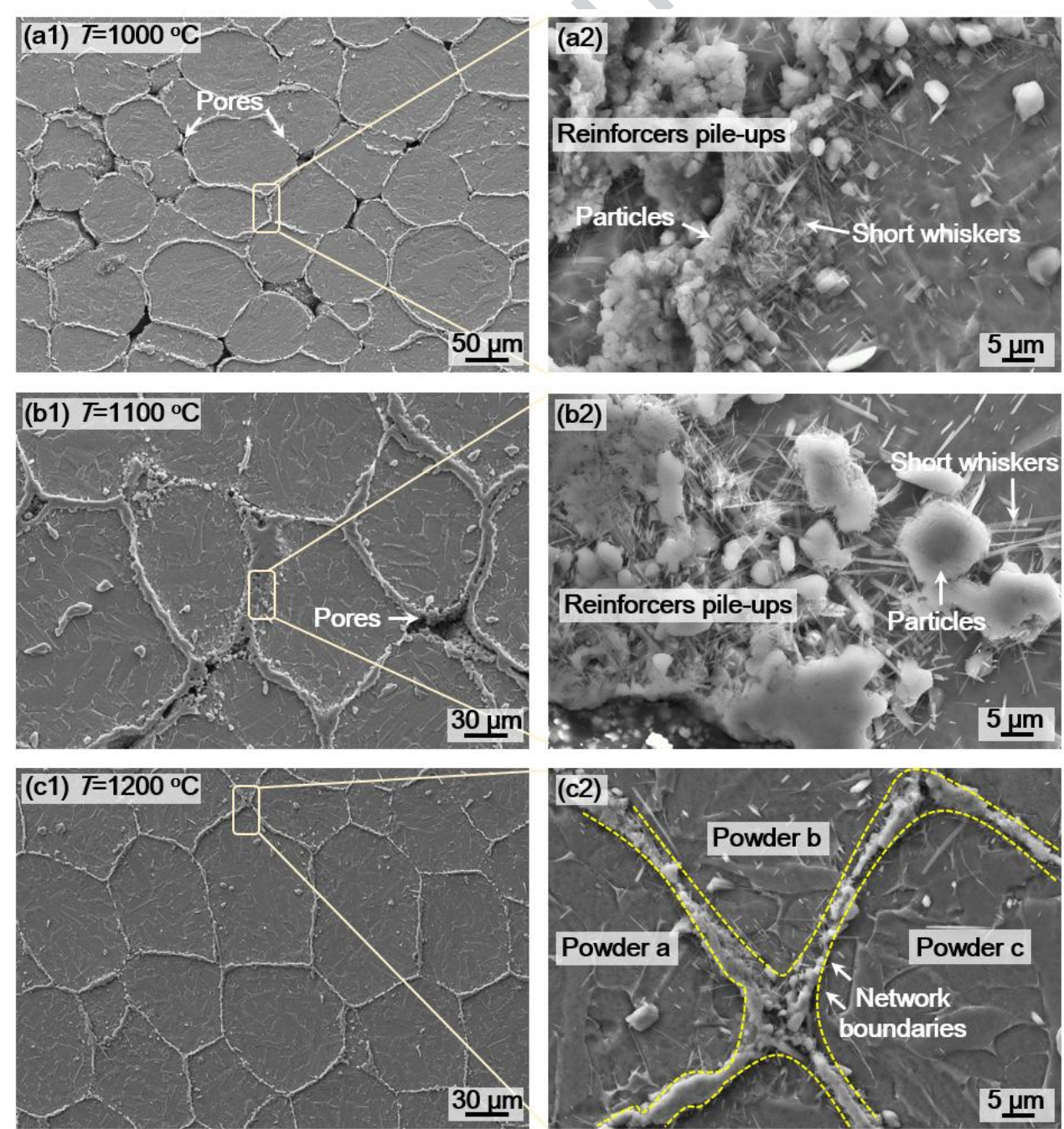
Figure 4 | SEM micrographs for Ti-6Al-4V/(TiC+TiB) composites sintered at various temperatures under $25 \mathrm{MPa}$ for 60 min: (a1) and (a2) $1000^{\circ} \mathrm{C}$; (b1) and (b2) $1100^{\circ} \mathrm{C}$; (c1) and (c2) $1200^{\circ} \mathrm{C}$.

XRD phase identification results (Fig. 5 (b)) suggest that TiC and TiB were formed during the sintering procedure and no diffraction patterns of graphite or $\mathrm{TiB}_{2}$ are detected which convinces that the two in-situ chemical reactions (Eqs. (1) and (2)) have completely taken place at $1200{ }^{\circ} \mathrm{C}$. The combined EDS analyses (Fig. 5 (d)) and morphological observation after etching out the matrix (Fig. 5 (c)) reveal that TiB and TiC respectively demonstrate needle-like whisker and particulate geometry, for which the corresponded formation mechanisms are schematically displayed in Fig. 5 (a). Such reinforcer configuration is expected to bring together the benefits of both TiB and TiC: the whiskers-shaped TiB that grow into the adjacent Ti-6Al-4V powders enhance the connectivity of matrix; while the TiC strengthened the network configuration by clustering into the wall-shape configuration. The effect of reinforcer addition on matrix microstructure, strengthening mechanisms, and fracture modules will be discussed in detail in section 4. 
(a) In-situ chemical reaction
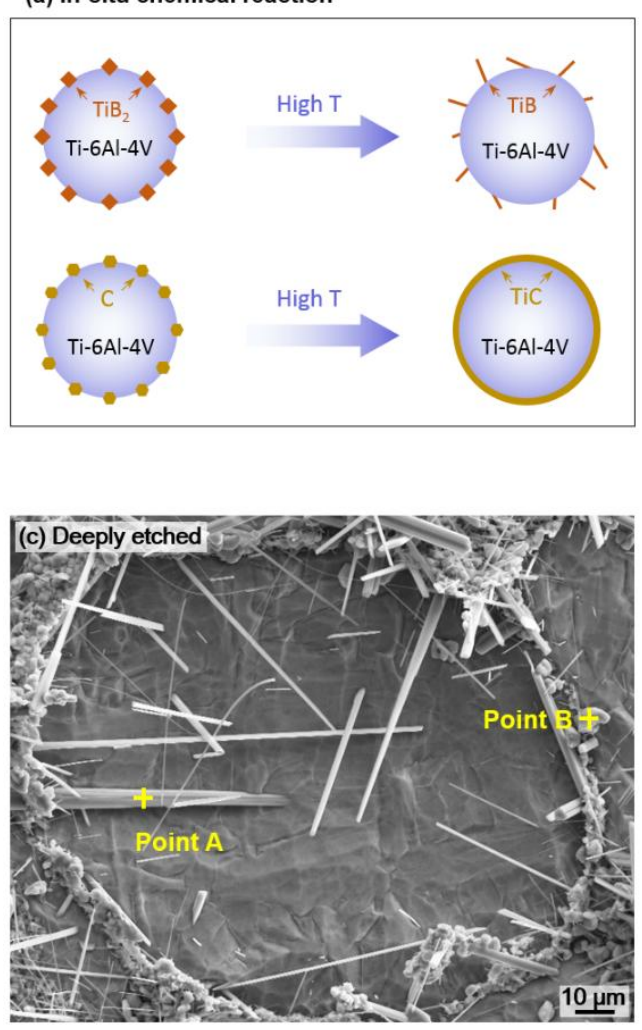

(b) Phase constitution
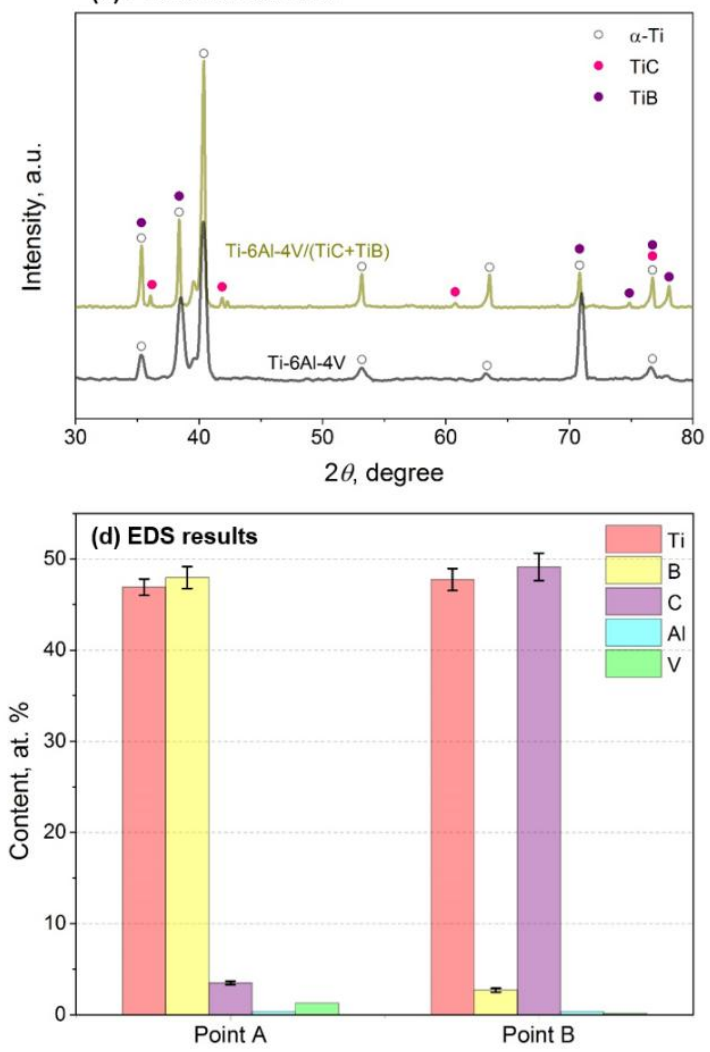

Figure $5 \mid$ Phase constitution and microstructure of Ti-6Al-4V/(TiC+TiB) composites fabricated under optimized processing conditions: (a) mechanistic schematics of TiB and TiC formation; (b) XRD patterns for composites and Ti-6Al-4V alloy; (c) SEM image of reinforcer morphology; (d) EDS point scan of selected spots denoted in as "point $A$ " and "point $B$ " in (c).

EDS elemental mapping results of a selected area of interest indicate a relatively homogenous distribution of $\mathrm{Ti}$ within the matrix (Fig. 6 (b)). Alloying element Al (Fig. 6 (c)) and V (Fig. 6 (d)) exhibit an opposite partition characteristic, the former enriches in the $\alpha$ phase while the latter segregates in to the $\beta$ phase. Both $\mathrm{C}$ and $\mathrm{B}$ accumulate at the network boundary regime which again proves the fact that $\mathrm{TiC}$ and $\mathrm{TiB}$ contribute to the hybrid network configuration. Interestingly, several C-enrichment spots are also detected in Fig. 6 (e), a further comparison between Fig. 6 (b) and (c) implies that these regimes are depleted in Al while preserving the similar Ti content as the matrix, which indicates the existence of TiC within the network. This is mostly attributed to the fact that at an elevated sintering temperature of $1200{ }^{\circ} \mathrm{C} \mathrm{C}$ atoms are sufficiently mobile to diffuse from graphite then dissolve into the matrix Ti-6Al-4V alloy, and upon cooling (Fig. 3 (a)), the excess C consequently precipitates out 
from the matrix, giving rise to the formation of TiC within the network. Because of carbon dissolution, lattice

parameters of the matrix Ti-6Al-4V alloy is also altered, as confirmed from the left-shift of diffraction peaks in Fig.

5 (b). Such phenomena subsequently result in carbon interstitial solute strengthening within the

Ti-6Al-4V/(TiC+TiB) composites, for which a semi-quantitative assessment can be found in section 4.2 (a).
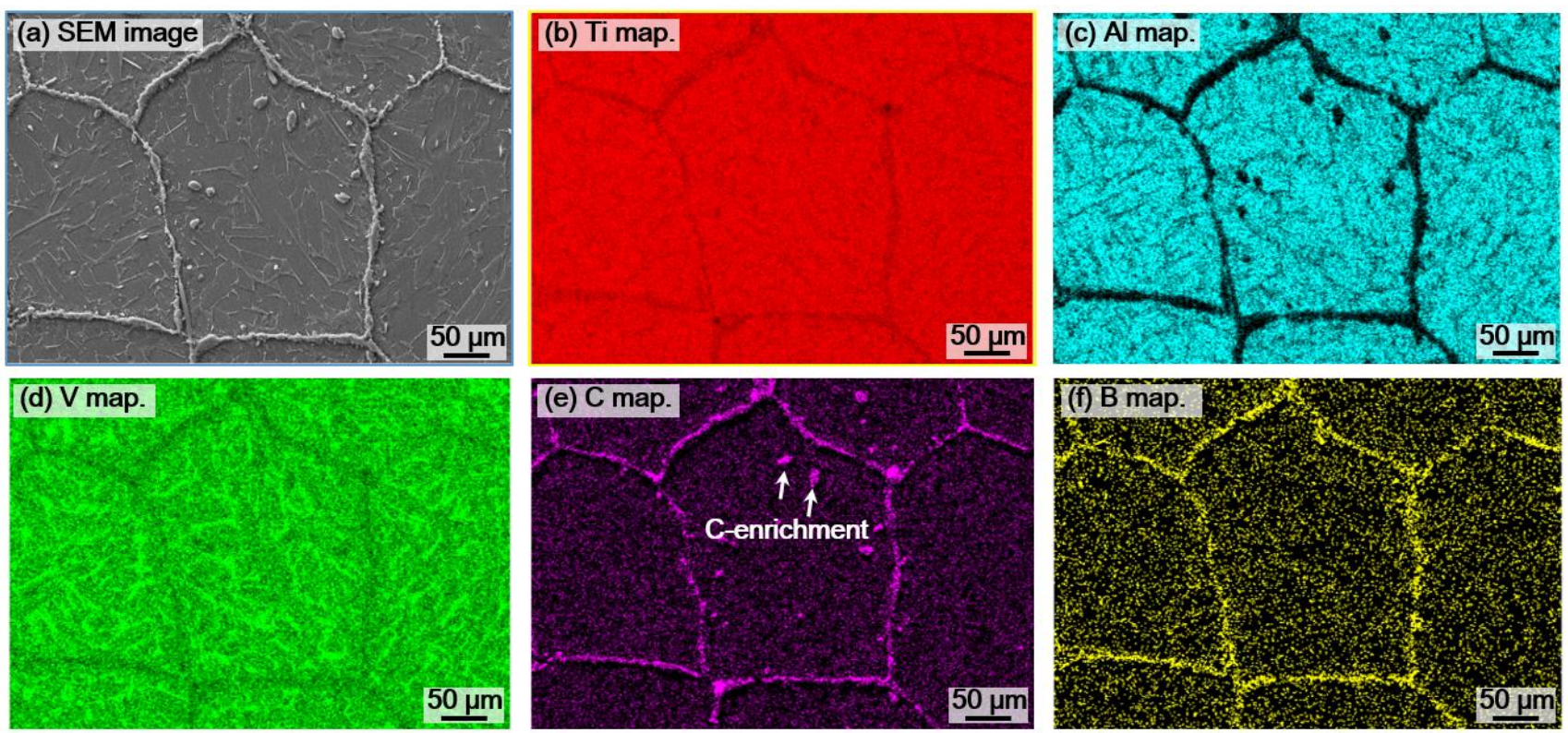

Figure 6| Meso-scale elemental distribution characteristics: (a) SEM micrograph of the selected area of interest; (b)-(f) Ti, Al, V, C, and B mappings.

It is revealed by the high-resolution TEM (HRTEM) characterization results of $\alpha$-Ti/TiB and $\alpha$-Ti/TiC interfaces

that both $\mathrm{TiB}$ and $\mathrm{TiC}$ form strong metallurgical bonds with the adjacent matrix (Figs. 7 (a) and (b)), and no extra interfacial reaction product is detected. The corresponded fast Fourier transformation (FFT) analyses of the HRTEM micrographs reveal that TiC and $\alpha$-Ti exhibit an orientation relationship of $(\overline{2} 00)_{\mathrm{TiC}} \|(\overline{2} 110)_{\alpha-\mathrm{Ti}}$, $[001]_{\mathrm{TiC}} \|[01 \overline{1} 0]_{\alpha-\mathrm{Ti}}$, while in contrast orientation relationship between TiB and $\alpha$-Ti demonstrates a subtle deviation from $(201)_{\mathrm{TiB}}\left\|(\overline{1} 110)_{\alpha-\mathrm{Ti}},[11 \overline{2}]_{\mathrm{TiC}}\right\|[0001]_{\alpha-\mathrm{Ti}}$. 

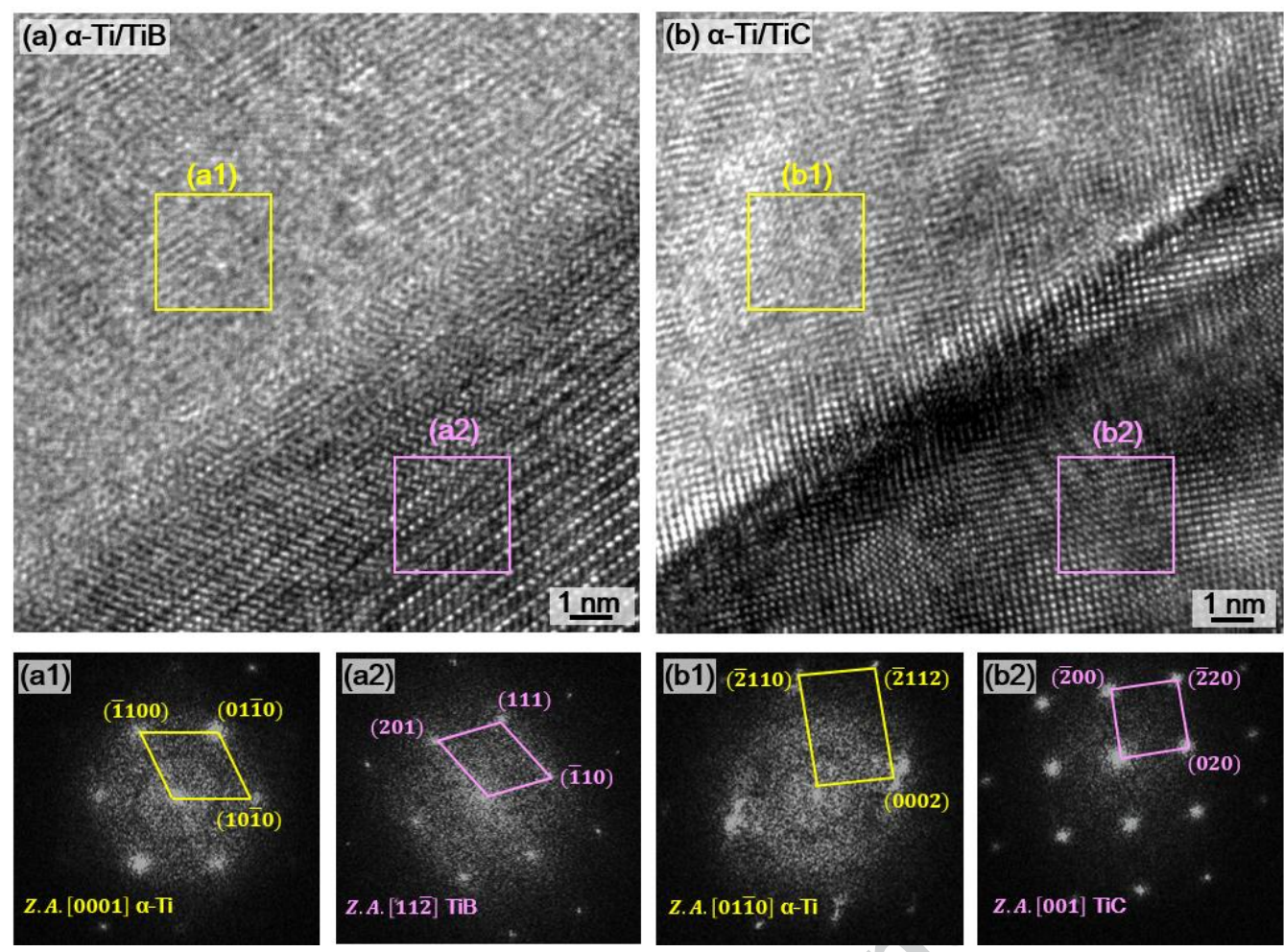

Figure 7| HRTEM characterization of reinforcer/matrix interface: (a) $\alpha$-Ti/TiB interface; (b) $\alpha$-Ti/TiC interface; (a1) and (a2) FFT analyses of selected area in (a); (b1) and (b2) FFT analyses of selected area in (b).

\subsection{High-temperature tensile properties}

Fig. 8 presents the tensile curves of the composites with three different network configurations under testing temperatures of $500,550,600$, and $650{ }^{\circ} \mathrm{C}$. All three composites exhibit a decrease in ultimate tensile strength (UTS) while an increase in fracture elongation with respect to increasing temperature. The composites with $50 \mu \mathrm{m}$ network diameter show the highest UTS at 500 and $600{ }^{\circ} \mathrm{C}$ (788 and $626 \mathrm{MPa}$ respectively) given the slightly lower UTS compared to the ones with $100 \mu \mathrm{m}$ network diameter at 550 and $650{ }^{\circ} \mathrm{C}$. It is also recognized that the composites with the largest network diameter $(140 \mu \mathrm{m})$ display the lowest UTS at all tested temperatures $(699,637$, 534, and 446 MPa respectively). Furthermore, the composites with the smallest network diameter (50 $\mu \mathrm{m})$ possess superior fracture elongation to the other two composites. Comparisons amongst the tensile properties of the present Ti-6Al-4V/(TiC+TiB) composites, solely TiB reinforced Ti-6Al-4V composites, and monolithic Ti-6Al-4V alloys are demonstrated in Fig. 9 (note that network size of the Ti-6Al-4V/TiB composite is $110 \mu \mathrm{m}$ and the monolithic 
Ti-6Al-4V alloys were fabricated from $85 \mu \mathrm{m}$ raw powders). It can be seen that all three Ti-6Al-4V/(TiC+TiB) composites exhibit enhanced UTS compared to Ti-6Al-4V alloys and Ti-6Al-4V/TiB composites, among which the $50 \mu \mathrm{m}$ network ones show comparable fracture elongation to Ti-6Al-4V/TiB composites. These results imply that by constructing 5 vol. \% hybrid (TiC+TiB) network reinforcers and appropriately manipulating its dimension, dramatic enhancement in high-temperature tensile strength can be achieved without inducing catastrophic ductility sacrifice.
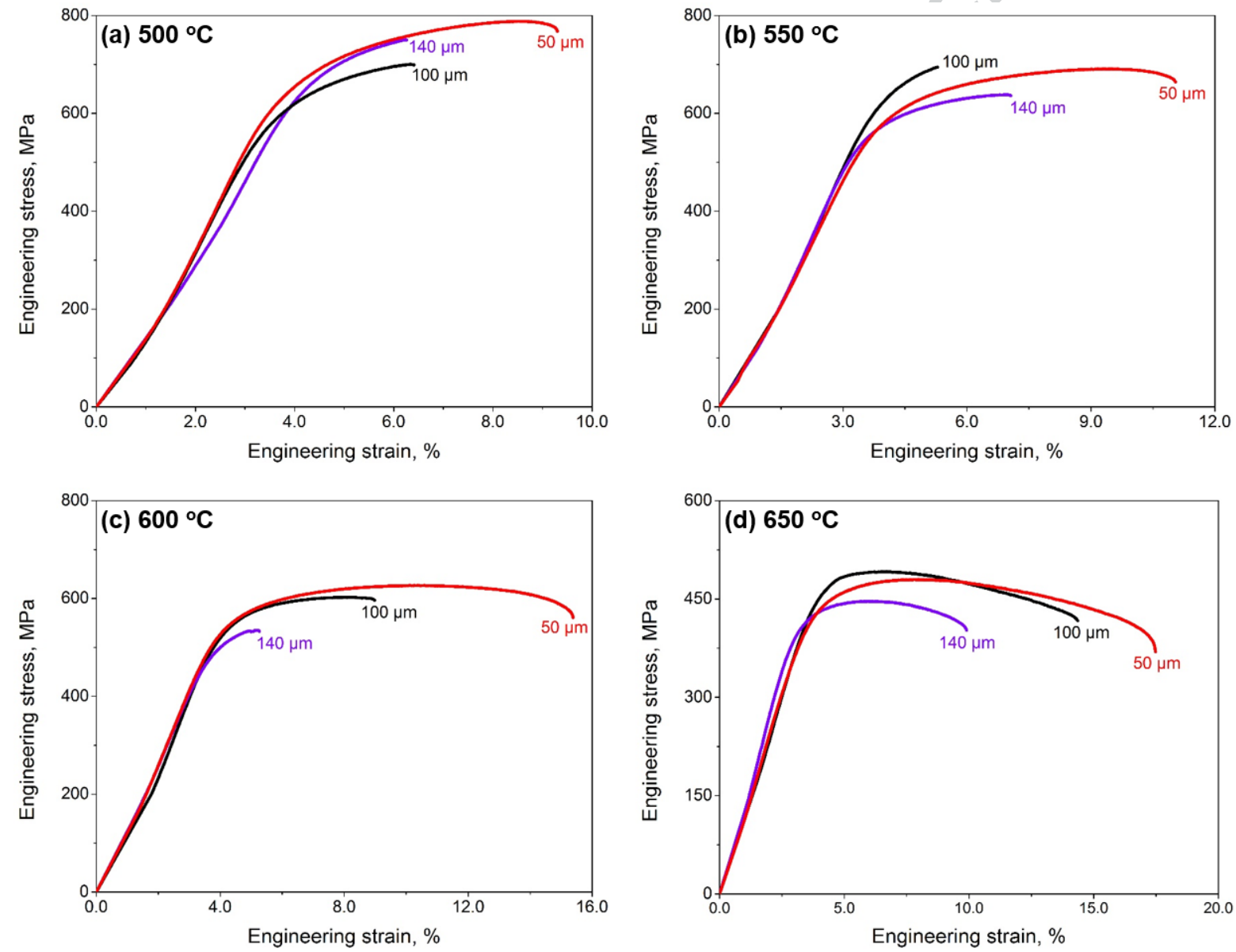

Figure $8 \mid$ High-temperature tensile properties of Ti-6Al-4V/(TiC+TiB) composites with various network diameters: (a) $500^{\circ} \mathrm{C}$; (b) $550^{\circ} \mathrm{C}$; (c) $600^{\circ} \mathrm{C}$; and (d) $650^{\circ} \mathrm{C}$. 
(a)

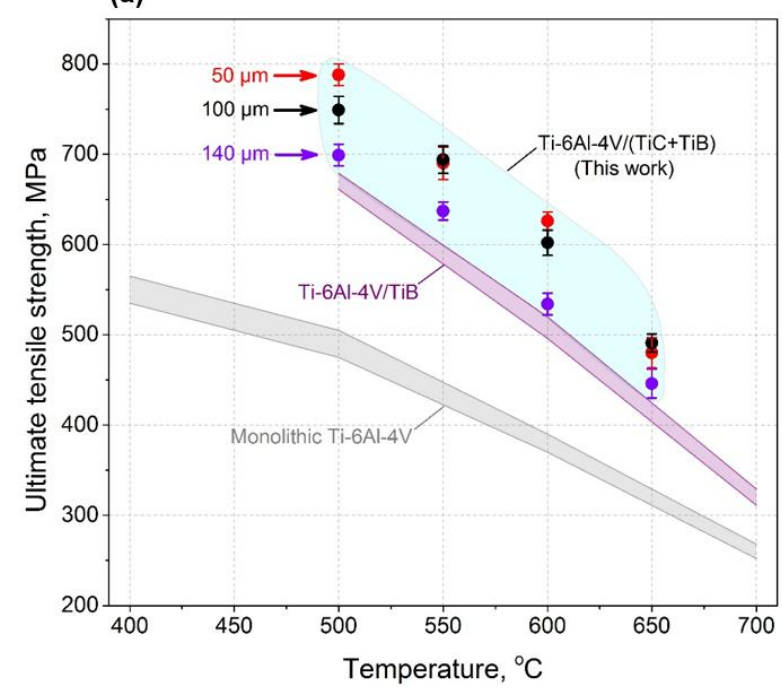

(b)

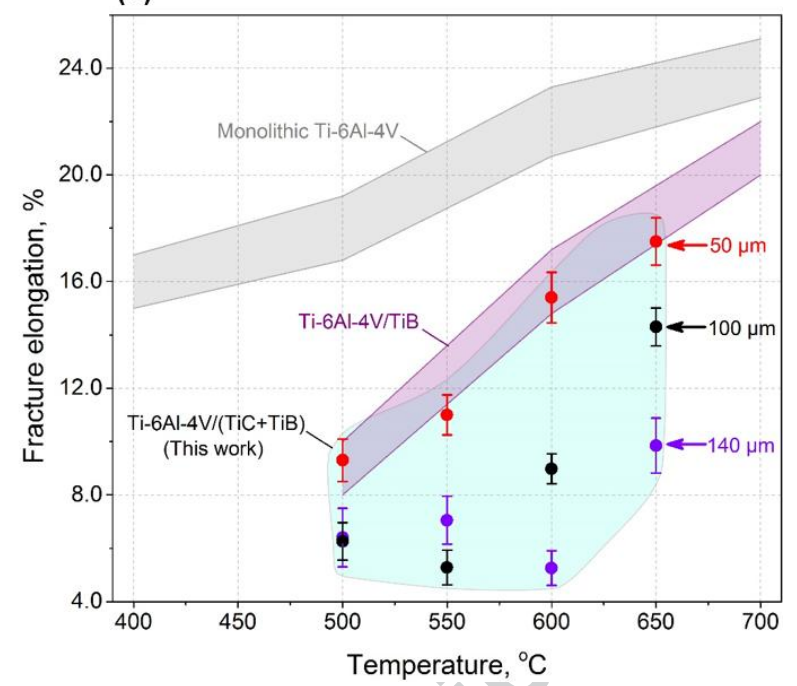

Figure 9 | Tensile property comparison amongst Ti-6Al-4V/(TiC+TiB) composites, Ti-6Al-4V/TiB composites (network size: $110 \mu \mathrm{m})^{[37]}$, and monolithic Ti-6Al-4V alloys (fabricated from $85 \mu \mathrm{m}$ raw powders) ${ }^{[15]}$ at elevated temperatures: (a) ultimate tensile strength; (b) fracture elongation.

\section{Discussion}

\subsection{Reinforcer-assisted grain refinement}

As has been revealed from the microstructure and porosity evolution characteristics (Fig. 4) that the applied pressure, temperature, and densification time are optimized as $25 \mathrm{MPa}, 1200{ }^{\circ} \mathrm{C}$, and $60 \mathrm{~min}$. Compared to the microstructure of as-sintered monolithic Ti-6Al-4V alloy under the same conditions, all three composites exhibit significantly refined $\alpha$-grain size (Fig. 10). Insets in Fig. 10 illustrate the grain size distribution characteristics in these four materials (at least 50 grains were brought into statistical analysis), and the corresponded average grain size values are summarized in Tab. 3 The contribution of reinforcer introduction to the observed $\alpha$-grain refinement can be understood through the following two-fold mechanisms: (1) Extensive heterogeneous nucleation sites. According to the equilibrium phase constitution calculation shown in Fig.3 that the formation of $\alpha$-grain originates from the $\beta$-to- $\alpha$ transformation upon cooling whose kinetics has been well documented to be controlled by nucleation and growth procedures ${ }^{[38,39]}$. Upon the incipience of such a transformation, the large fraction of reinforcer/matrix interface can act as energetically favored heterogeneous nucleation sites, and as a result of which, (C) 2019 The Minerals, Metals \& Materials Society and ASM International. 
promoting nucleation rate particularly near the network boundary (confirmed by the even finer grain size at such locations); and (2) Zener drag. Right after nucleation, the $\alpha$-grains will exhibit coarsening trend and the velocity of grain boundary depends on both local curvature and grain boundary energy. The addition of reinforcer, on the other hand, has also been realized to enable strong pinning effect on grain boundary, namely, the Zener drag ${ }^{[40]}$ :

$$
R^{e q \cdot} \propto \frac{R^{p}}{f}
$$

Which states that the equilibrium grain size $R^{e q}$ is proportional to the ratio between the spacing of pinning point $R^{p}$ and its fraction $f$. The Zener drag effect within the composites lead to more efficient suppression of grain growth than the intrinsic solute drag within the monolithic Ti-6Al-4V alloy. Compared with the average grain size in the solely TiB containing composites (network size $110 \mu \mathrm{m}$ ) reported in the literature (also see Tab. 3), the incorporation of TiC not only decreases $R^{p}$ through the formation of the wall-shaped configurations shown in Fig. 5, but also increases possible pinning point, which as a whole contribute to even finer $\alpha$-grain size. Interestingly, $\alpha$-grain size within the three $\mathrm{Ti}-6 \mathrm{Al}-4 \mathrm{~V} /(\mathrm{TiC}+\mathrm{TiB})$ composites examined in the present work exhibits decreasing trend with respect to decreasing network radius. Such a feature is mostly ascribed to the increasing effective pinning points per unit length (nominally the $f$ value) along the circumference of the network as its radius decreases. 

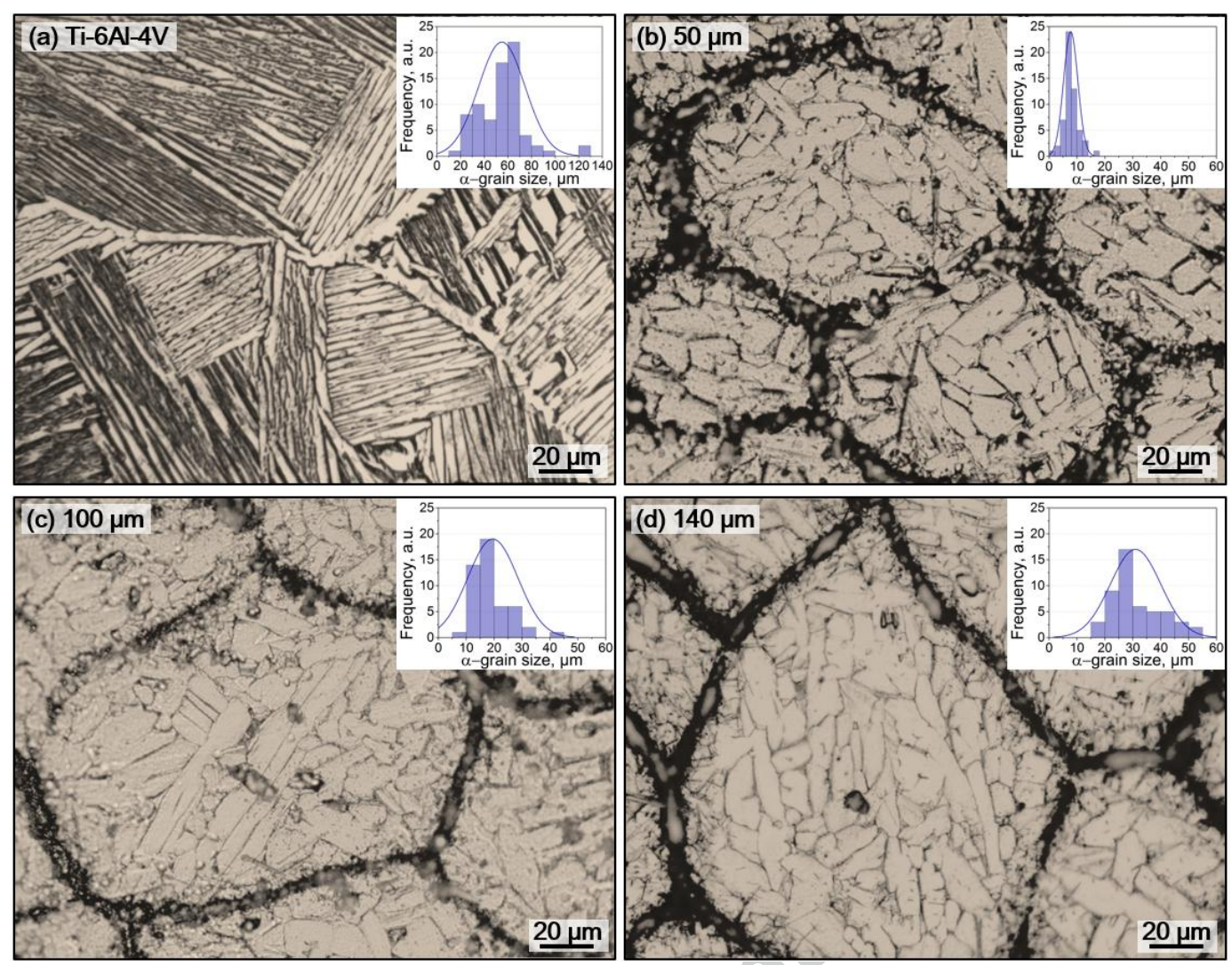

Figure 10 | OM images of $\alpha$-grain size in: (a) monolithic Ti-6Al-4V alloys; (b)-(d) Ti-6Al-4V/(TiC+TiB) composites with 50,100, and 140 um network diameter.

Table 3 | Summary of average $\alpha$-grain size within different materials

\begin{tabular}{ccc} 
Material category & Average $\alpha$-grain size $(\mu \mathrm{m})$ & Reference \\
\hline Ti-6Al-4V & $54.9 \pm 9.8$ & This work \\
Ti-6Al-4V/(TiC+TiB), $50 \mu \mathrm{m}$ network & $7.7 \pm 1.5$ & This work \\
Ti-6Al-4V/(TiC+TiB), $100 \mu \mathrm{m}$ network & $18.6 \pm 3.7$ & This work \\
Ti-6Al-4V/(TiC+TiB), $140 \mu \mathrm{m}$ network & $30.9 \pm 5.1$ & This work \\
Ti-6Al-4V/TiB, $110 \mu \mathrm{m}$ network & $26.7 \pm 2.6$ & [37]
\end{tabular}

\subsection{Strengthening mechanisms}

Fig. 9 demonstrate the comparison of ultimate tensile strength and fracture elongation amongst the present Ti-6Al-4V/(TiC+TiB) composites, the solely TiB reinforced composites, and the monolithic Ti-6Al-4V alloys. At 
all testing temperatures, the $\mathrm{Ti}-6 \mathrm{Al}-4 \mathrm{~V} /(\mathrm{TiC}+\mathrm{TiB})$ composites exhibit significantly higher tensile strength compared to the matrix Ti-6Al-4V alloy and the Ti-6Al-4V/TiB composites. Potential strengthening modules including solid solution strengthening, Hall-Petch strengthening, dislocation strengthening, and dispersoid strengthening will be discussed semi-quantitatively to elucidate the strength enhancement in the Ti-6Al-4V/(TiC+TiB) composites.

\section{(a) Interstitial solute strengthening}

As mentioned in the experimental section, $\mathrm{TiB}_{2}$ and graphite powders were utilized as the reactants for introducing in-situ TiB and TiC reinforcers. In addition to the two in-situ chemical reactions, dissolution of B and C into the matrix will simultaneously take place at during the sintering procedure. According to the mixing thermodynamics

${ }^{[41]}$, B exhibits negligible solubility in $\alpha$-Ti phase (the dominate matrix phase at ambient temperature) because of its strong propensity for $\mathrm{TiB}$ formation; in contrast, solubility of $\mathrm{C}$ in $\alpha$ - $\mathrm{Ti}$ is comparatively higher (also confirmed in Fig. 3 (a)). Direct evidence of such distinction can be found in Fig. 6 (e), where carbon enrichment spots exist in the bulk of the matrix powder, indicating the dissolution history of carbon atoms at elevated temperature, although the excess quantity has precipitated out as carbides during the annealing process. The XRD patterns displayed in Fig. 5 (b) were further Rietveld refined (using the MAUD software http://maud.radiographema.eu/) during which (0002) and (10 $\overline{1} 0)$ diffraction peaks were utilized to determine the variation in lattice parameters $c$ and $a$ for both the Ti-6Al-4V/(TiC+TiB) composites (50 $\mu \mathrm{m}$ as a representative) and the monolithic Ti-6Al-4V alloy. As suggested by the calculation results in Tab. 4, carbon dissolution results in a dramatic increase in $c(\sim 0.33 \%)$ compared to the subtle increment in $c(\sim 0.039 \%)$ the integrated effect of which gives rise to $\sim 0.41 \%$ volumetric expansion. With regard to these two observations, the Ti-6Al-4V/(TiC+TiB) composites benefit from extra carbon solute strengthening as predicted by the Fleischer equation ${ }^{[42]}$ : 
where $m, G, b, x_{\mathrm{C}}$ represent the Taylor factor, shear modulus, magnitude of Burgers vector, and carbon weight fraction for the matrix Ti-6Al-4V alloy. The lattice distortion strain $\varepsilon_{s s}$ can be subsequently calculated as the relative change in lattice parameter with respect to carbon addition: $\varepsilon_{S S}=\frac{\delta a / \delta x_{\mathrm{C}}}{a_{0}}$ in which $a$ and $a_{0}$ are lattice parameters with and without carbon dissolution. It shall be noted that at high-temperatures, matrix softening, lattice expansion, together with variation in carbon solubility will alter the carbon interstitial strengthening effect.

Table 4 | Lattice parameters of $\alpha-T i$ in Ti-6Al-4V alloy and Ti-6Al-4V/(TiC+TiB) composites at ambient temperature

\begin{tabular}{ccccc} 
& $c(\AA)$ & $a(\AA)$ & $V\left(\AA^{3}\right)$ & $c / a$ \\
\hline Ti-6Al-4V & 4.671694 & 2.931244 & 34.7623 & 1.59376 \\
Ti-6Al-4V/(TiC+TiB) & 4.687342 & 2.932305 & 34.9040 & 1.59852 \\
Relative variation $(\%)$ & +0.33459 & +0.03961 & +0.4077 & +0.29866
\end{tabular}

\section{(b) Hall-Petch strengthening}

Discussion on microstructural evolution during sintering process already highlights the significant role of TiB and TiC reinforcers in $\alpha$-grain refinement. The formation of extensive fraction of grain boundaries leads to the impedance of dislocation motion and slip transfer between two adjacent grains, which in turn contributes to strengthening. The grain boundary strengthening effect is usually described by the Hall-Petch equation ${ }^{[43]}$ :

$$
\Delta \sigma_{H-P}=\sigma_{0}+k_{H-P} D^{-1 / 2}
$$

where $\sigma_{0}, k_{H-P}$, and $D$ are intrinsic friction stress, Hall-Petch constant, and grain size. Albeit Ti-6Al-4V alloy exhibits dual phase microstructure and the relevant $k_{H-P}$ value is rather scant in the literature particularly at elevated temperatures, a rough estimation of relative strength variation can be accomplished by utilizing the $\alpha$-grain size values listed in Tab. 3 together with the $\sigma_{0}(250 \mathrm{MPa})$ and $k_{H-P}\left(190 \mathrm{MPa} / \mu m^{2}\right)$ values of pure Ti at ambient temperature ${ }^{[44-47]}$. It is recognized from the calculation results (Fig. 11) that the Ti-6Al-4V/(TiC+TiB) 
composites fabricated from the smallest matrix powder size exhibit the most significant Hall-Petch strengthening: approximately $15.7 \%(43.3 \mathrm{MPa})$ and $11.3 \%$ (32.3 MPa) increase compare to the monolithic Ti-6Al-4V alloy and the Ti-6Al-4V/TiB composites, agreeing well with the tensile strength evolution trend summarized in Fig. 11. Such theoretical estimation further implies that utilization of finer Ti-6Al-4V matrix powders could be an efficient approach to achieve more desirable strengthening effect.

\section{(c) Dislocation strengthening}

Dislocations entanglement with themselves can also lead to the suppression of their mobility and thereby contribute to strengthening. According to the Bailey-Hirsch equation, dislocation density is the dominant factor that controls the strengthening effect ${ }^{[48]}$ :

$$
\Delta \sigma_{\text {disloc. }}=m \alpha G b \rho^{1 / 2}
$$

Where $m, \alpha, G, b$, and $\rho$ denote Taylor factor, structural constant, shear modulus, magnitude of Burgers vector, and dislocation density (including both statistically storaged dissociations and geometrically necessary dislocations). In the present study, since all the composites have been extensively annealed before tensile tests, the residual dislocation density are comparatively low, indicating the minor contribution of dislocation entanglement strengthening to yield strength compared with other mechanisms. It shall be noted that such intrinsic defect characteristics also imply that dislocation strengthening in the present composites exhibits source-limited kinetics: strength enhancement is mostly ascribed to the activation of dislocation multiplication source. 


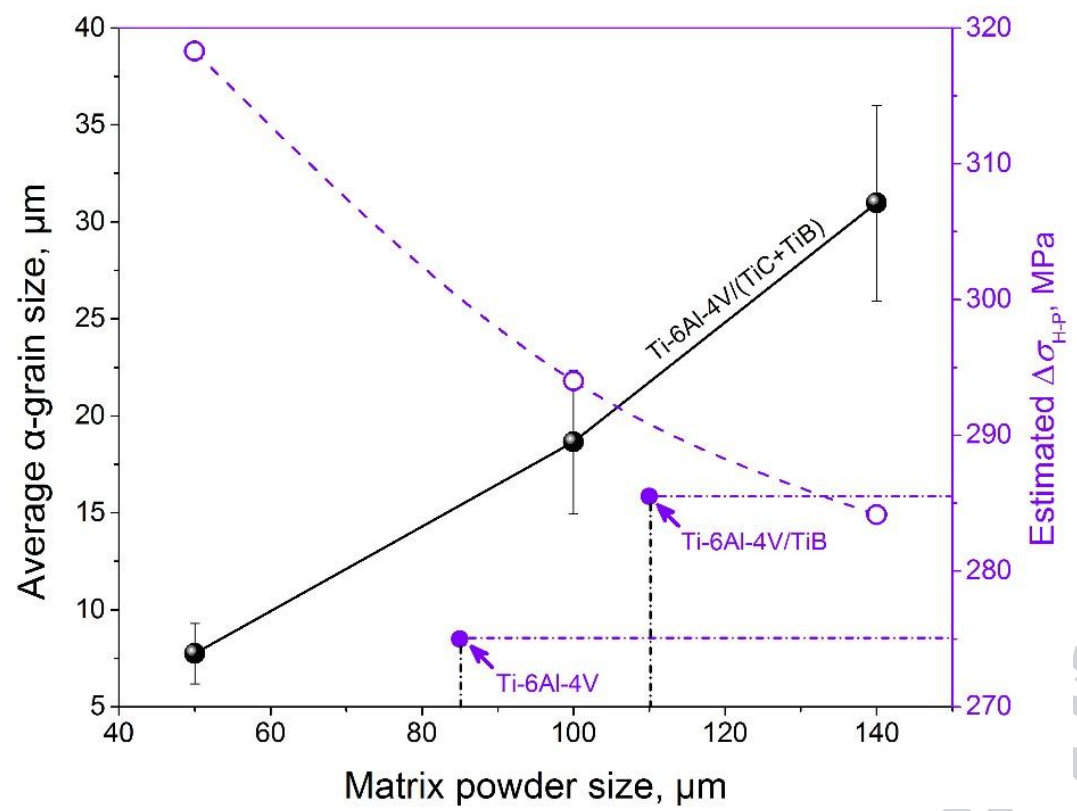

Figure 11 | Theoretical estimation of Hall-Petch strengthening in Ti-6Al-4V/(TiC+TiB) composites, Ti-6Al-4V/TiB composites (network size $110 \mu \mathrm{m}$ ), and monolithic Ti-6Al-4V alloys (fabricated form $85 \mu \mathrm{m}$ raw powders)

(d) Dispersoid strengthening

Since network distributed (TiC+TiB) reinforcers were introduced into the present composite through in-situ chemical reaction, dispersoid strengthening originated from secondary particle-dislocation interaction is supposed to be of great significance in strength enhancement. The nominal dispersoid strengthening effect can be categorized into two sub-branches: Orowan strengthening $\left(\Delta \sigma_{\text {Orowan }}\right)$ and load-transfer strengthening $\left(\Delta \sigma_{L T}\right)$ :

$$
\Delta \sigma_{\text {disper. }}=\Delta \sigma_{\text {orowan }}+\Delta \sigma_{L T}
$$

In which Orowan strengthening describes the strength gaining from dislocations bypass secondary particles ${ }^{[48]}$.

$$
\Delta \sigma_{\text {Orowan }}=m \frac{\beta G b}{\pi \sqrt{1-v}} \frac{1}{\lambda_{p}} \ln \left(\frac{d_{0}}{b}\right)
$$

where $m, \beta, G, b$, and $v$ are Taylor factor, structural constant, shear modulus, magnitude of Burgers vector, and Poisson's ratio of the substrate; $\lambda_{p}$ and $d_{0}$ respectively denote the average distance and the size of secondary particles. Owing to the formation of densely distributed particulate-shaped TiC reinforcers, $\lambda_{p}$ of the 
higher strength in the former composites even provided that $d_{0}$ remains almost unchanged. Moreover, as seen from Fig. 10 Ti-6Al-4V/(TiC+TiB) composites produced from smaller powders display more uniform reinforcer distribution, which consequently lead to more effective strengthening.

Since both $\mathrm{TiC}$ and $\mathrm{TiB}$ form strong metallurgical bonds with their adjacent Ti-6Al-4V matrix (Fig. 7), indicating the occurrence of effective load transfer from matrix to reinforcers ${ }^{[49]}$ :

$$
\Delta \sigma_{L T}=0.5 f^{V} \sigma_{0.2}^{\text {matrix }}
$$

where $f^{V}$ and $\sigma_{0.2}^{\text {maxtrix }}$ are reinforcer volumetric fraction and yield strength of matrix. considering the network distribution characteristics in the present composites, a microstructural-based parameter $f^{\text {loc. }}$ is introduced to describe the local reinforcer content (the corresponded derivation is presented in supplemental information):

$$
f^{l o c .}=\frac{1}{1-(1-\delta / R)^{3}} f^{\text {nom }}
$$

Where $\delta$ and $R$ are thickness and radius (approximately the radii of raw powders) of the network configuration, $f^{\text {loc. }}$ and $f^{\text {nom. }}$ refer to local and nominal reinforcer volumetric fractions. Combining Eqs. (12) and (13), it is recognized that under the condition of same nominal reinforcer content, load transfer is more effective within composites with larger network size (fabricated from larger powders). It shall be noted that such a characteristic can induce unfavorable local-embrittlement problem, leading to deteriorated ductility and facilitate crack propagation, for which the mechanisms will be discussed in detail in section 4.3.

To briefly sum up, the introduction of hybrid ( $\mathrm{TiC}+\mathrm{TiB})$ composites effectively enhance the tensile strength mainly through carbon interstitial dissolution, grain refinement, and dispersoid strengthening, the corresponded net 
contribution can be theoretically predicted by using the Clyne equation ${ }^{[19]}\left(\Delta \sigma_{i}\right.$ denotes the $i$ th strengthening mechanism):

$$
\Delta \sigma_{n e t}=\left(\sum_{i}^{n} \Delta \sigma_{i}\right)^{1 / 2}
$$

It should be noted that in the present work, while Eq. (14) is adopted to phenomenologically demonstrate the prediction of net strengthening effect, due to the lack of key physical parameters at elevated temperatures (such as the Hall-Petch coefficient, shear modulus, and the magnitude of Burgers vector), a more quantitative temperature-dependent assessment of the contribution from each mechanism still remain to be further explored.

\subsection{Fracture modules}

As revealed by the fractography and fracture cross-sectional morphology, at temperatures lower than $550{ }^{\circ} \mathrm{C}$, typical brittle-like fracture characteristics can be observed (Fig. 12 (a)), whereas at an elevated temperature of 650 ${ }^{\circ} \mathrm{C}$ matrix tearing occurs, giving rise to ductile fracture which consequently leads to the ductility enhancement (Fig. 12 (c) and (d)) The fracture mechanisms within the present Ti-6Al-4V/(TiC+TiB) composites can be understood from both crack nucleation and propagation aspects. Compared to the $\alpha / \beta$ interface within the matrix Ti-6Al-4V alloy, strain partitioning exhibits more inhomogeneous characteristics at the reinforcer/matrix interface owing to the more distinctive discrepancy in strength, modulus, and strain hardenability, leading to deformation incompatibility. Because of this, microcracks will always start to nucleate at the latter position so as to mitigate the strongly localized incompatible strain. The coalescence and thereby propagation of these microcracks can be phenomenologically understood from the Griffith theory ${ }^{[50]}$, which states that the nominal driving force for crack propagation is a cumulative effect of actual driving force and energy barrier. In the present composites (schematically shown in Fig. 13 (b)), crack can propagate along the reinforcer/matrix interface (path I), through the matrix (path II), or cut across reinforcers (path III) ${ }^{[50]}$ : 


$$
\phi^{i}=-\Omega+2 \Gamma^{i}
$$

where $\phi^{i}, \Omega$, and $\Gamma^{i}$ are the nominal driving force for cracking propagation through $i$ th path, far-field driving force, and energy barrier for creating two new surfaces through $i$ th mechanism (sign conventions follow thermodynamics, where $\Omega$ and $\Gamma^{i}$ are naturally positive). Since the far-field driving force can be approximately as a universal value for all three mechanisms, the cracking modules mostly rely on the temperature-dependent energy barrier term.
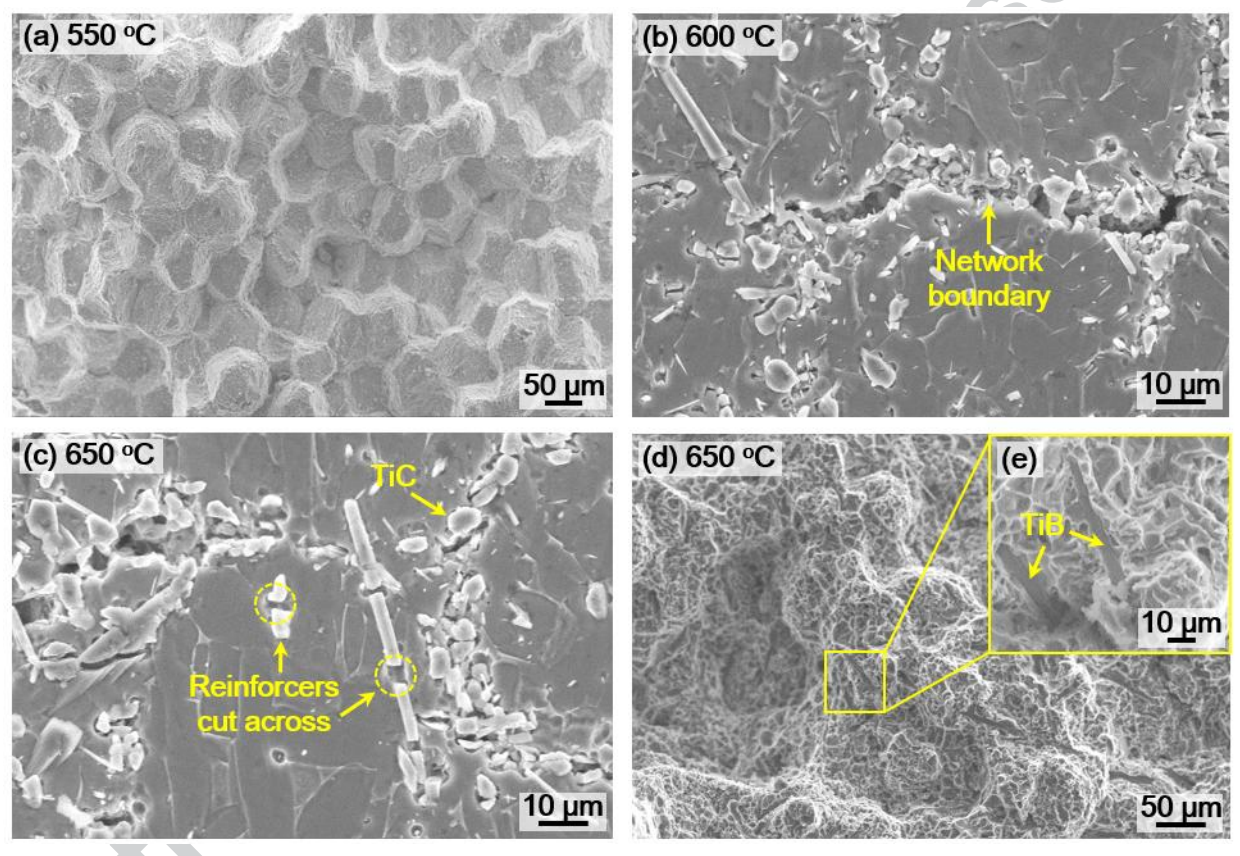

Figure 12 | Representative fracture morphology of Ti-6Al-4V/(TiC+TiB) composites at various temperatures: (a) fracture surface at $550{ }^{\circ} \mathrm{C} ;\left(\right.$ b) and (c) fracture cross-sections at 600 and $650{ }^{\circ} \mathrm{C} ;\left(\right.$ d) fracture surface at $650^{\circ} \mathrm{C} ;(e)$ higher magnification image showing matrix tearing cracking.

As depicted in Fig. 13 (a), at ambient or lower testing temperatures (500-550 ${ }^{\circ} \mathrm{C}$, Fig. 12 (a)), energy barrier for cracking through the matrix shows significantly higher value to the other two mechanisms because of energy dissipation upon plastic incipience. Owing to the strain hardenability difference and localized incompatibility, cracking along reinforcer/matrix interface is more energetically favorable compared to cutting through either TiC 
or TiB. Because of this, at relatively lower testing temperatures $\left(500\right.$ and $\left.550{ }^{\circ} \mathrm{C}\right)$ brittle-like fracture morphologies are observed, in particular, Fig. 12 (a) clearly reveals that the fractographic characteristic length scale is almost the same as the network diameter which further validates the proposed mechanisms. As temperature rises, the energy barrier for cracking through metal matrix exhibits a significant decreasing trend owing to the inferior physicochemical stability of the metallic phase and the decreasing bonding strength at elevated temperatures. While in contrast, ceramic reinforcers often possess excellent thermodynamic and mechanical stability at high-temperatures, leading to only subtle change in the energy barrier for crack propagation (Fig. 13 (a)). The integrated effect leads to more frequently observed cracking incidence of matrix tearing and subsequently ductile fractography (Fig. 12 (d)). It shall be noted that increasing temperature also decreases the discrepancies amongst these three types of energy barrier, and because of this both cracking along reinforcer/matrix interface and through the reinforce occur at elevated temperatures (Fig. 12 (b)-(d)).

By combining phenomenological theories proposed above and the local reinforcer content concept (Eq. (13)), the difference in ductility amongst $\mathrm{Ti}-6 \mathrm{Al}-4 \mathrm{~V} /(\mathrm{TiC}+\mathrm{TiB})$ composites with various network configuration can be understood as follows: composites with larger network show comparatively higher local reinforcer content (creating extensive fraction of reinforcer/matrix interface). After the nucleation of microcracks, such a characteristic enhance the probability for crack to propagate along the reinforcer/matrix interface, which is nominally in equivalent to lower down the corresponded energy barrier (sketched as the dashed line in Fig. 13 (a)). As a result, composites with larger network size tends to exhibit inferior ductility in the present testing temperature range. 
(a)

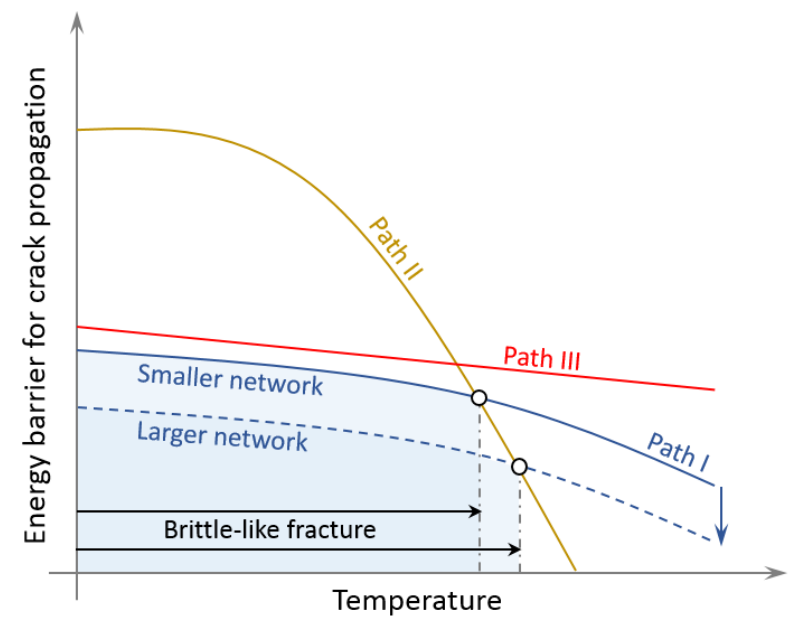

(b)

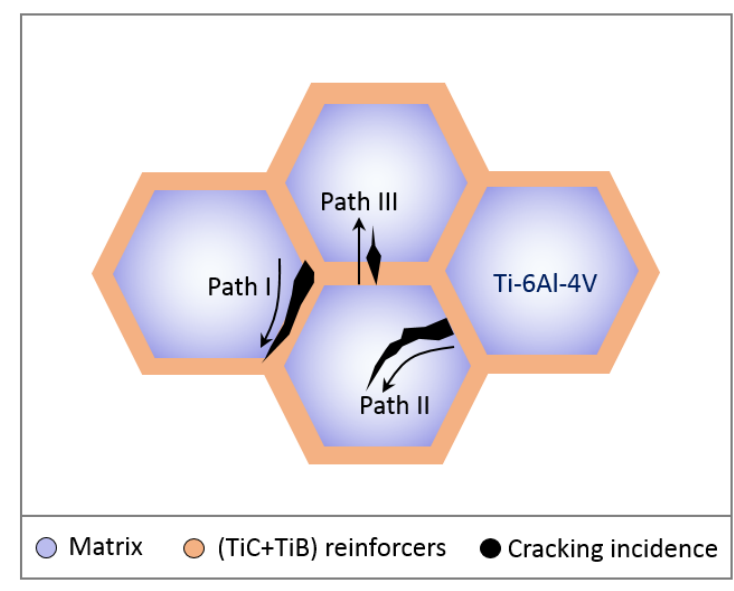

Figure 13 | Fracture mechanisms at elevated temperatures: (a) phenomenological schematics of energy barrier for cracking propagation along each pathway; (b) schematics of potential crack propagation modules.

\subsection{Insights into high-temperature titanium matrix composites design}

As demonstrated in sections 4.1-4.3, the construction of ( $\mathrm{TiC}+\mathrm{TiB})$ network through powder metallurgy processing drastically promotes the tensile properties of Ti-6Al-4V alloys at elevated temperatures. Fig. 14 provides a comparison amongst the present work and previous studies that fabricated similar composites via the conventional melting and casting technique ${ }^{[51,52]}$. It should be pointed out that, since the high-temperature tensile properties of cast $\mathrm{Ti}-6 \mathrm{Al}-4 \mathrm{~V} /(\mathrm{TiC}+\mathrm{TiB})$ composites are in lack in the literature, the present study introduces strengthening rate $\vartheta$ and elongation retention rate $\kappa$ to quantitatively assess the temperature-dependent strengthening efficiency for various composites. These two parameters are defined as follows at a certain temperature $T_{i}$ :

$$
\begin{aligned}
& \vartheta\left(T_{i}\right)=\frac{U^{\text {comp. }}-\text { UTS }^{\text {matrix }}}{\text { UTS }^{\text {matrix }}} \times 100 \% \\
& \kappa\left(T_{i}\right)=\left|\frac{\varepsilon_{f}^{\text {comp. }}-\varepsilon_{f}^{\text {matrix }}}{\varepsilon_{f}^{\text {matrix }}}\right| \times 100 \%
\end{aligned}
$$


Where UTS ${ }^{\text {comp. }}$,UTS ${ }^{\text {matrix }}, \varepsilon_{f}^{\text {comp. }}$, and $\varepsilon_{f}^{\text {matrix }}$ denote the ultimate tensile strengths and fracture elongations for composites and the corresponded matrix alloys. It is recognized from Fig. 14 that at all the surveyed temperatures, the present network strengthened $\mathrm{Ti}-6 \mathrm{Al}-4 \mathrm{~V} /(\mathrm{TiC}+\mathrm{TiB})$ composites demonstrate in general more effective strengthening rate than similar cast composites where Ti6242-type of alloys were utilized as the matrix. In the latter, however, the highest $\vartheta$ value achieved is only $29.2 \%$ while resulting in $79.1 \%$ retention in ductility. Even at a relatively higher temperature of $650{ }^{\circ} \mathrm{C}$ at least $50 \%$ strengthening rate can still be preserved in network Ti-6Al-4V/(TiC+TiB) composites in which smaller network geometries $(50$ and $100 \mu \mathrm{m})$ are constricted. In addition to the superior softening resistance at elevated temperatures, the network strengthened $\mathrm{Ti}-6 \mathrm{Al}-4 \mathrm{~V} /(\mathrm{TiC}+\mathrm{TiB})$ composites demonstrate milder ductility compensation especially in the $50 \mu \mathrm{m}$ network composites.

These observations bring about the following perspectives for future high-temperature titanium matrix composites investigation: (1) in addition to conventional melting-casting technique, powder metallurgy can also be considered as a promising processing route as it enables more flexibility in microstructural and structural control; and (2) under the concept of "reinforcer network configuration", high-temperature titanium alloys are suggested to substitute Ti-6Al-4V as the matrix, in such a way, more advanced performances at elevated temperatures can be realized. 


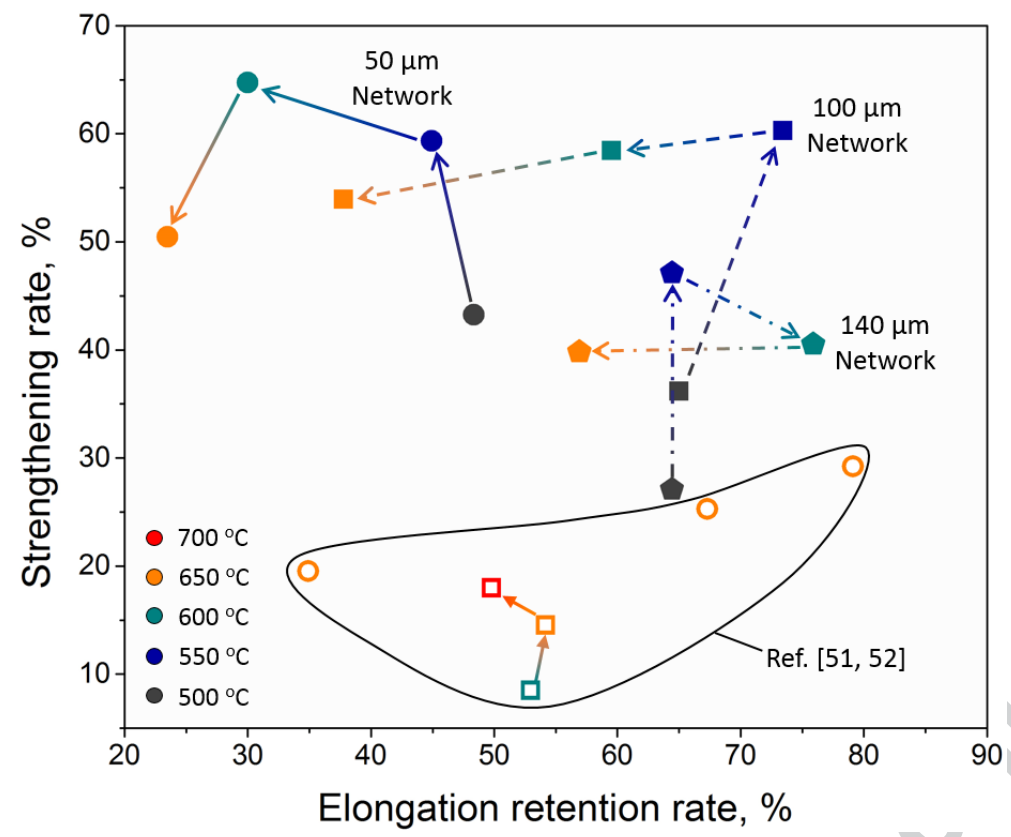

Figure $14 \mid$ Comparison amongst the present results and similar cast composites in the literature: solid symbols represent present study, while haloed symbols denote data excerpted from the reference ${ }^{[51,52]}$. Different colors (dark gray, blue, green, orange, and red) are utilized to highlight temperature and the arrows indicate increasing temperature.

\section{Conclusions}

In the present work, hybrid 5 vol. \% (TiC+TiB) network strengthened Ti-6Al-4V composites were fabricated through an integrated ball-milling and reaction hot pressing sintering technique. The corresponded optimal processing conditions, microstructural evolution characteristics, and high-temperature tensile properties were systematically examined. The major findings are summarized as follows:

(1) With the aid of phase equilibrium thermodynamic and densification kinetic prediction, $25 \mathrm{MPa}$ applied pressure, $1200{ }^{\circ} \mathrm{C}$ sintering temperature, 60 min sintering time are recognized as the optimal processing conditions for $\mathrm{Ti}-6 \mathrm{Al}-4 \mathrm{~V} /(\mathrm{TiC}+\mathrm{TiB})$ composites. The subsequent morphological observation and phase constitution assessment indicate that particulate $\mathrm{TiC}$ and whisker-like $\mathrm{TiB}$ forms along the margin of $\mathrm{Ti}-6 \mathrm{Al}-4 \mathrm{~V}$ powders giving rise to the network configuration; 
(2) High-temperature tensile testing results at $500,550,600$, and $650{ }^{\circ} \mathrm{C}$ suggest that the $\mathrm{Ti}-6 \mathrm{Al}-4 \mathrm{~V} /(\mathrm{TiC}+\mathrm{TiB})$ composites possess superior UTS compared to both the Ti-6Al-4V/TiB composites (network size $110 \mu \mathrm{m}$ ) and the monolithic Ti-6Al-4V alloys (fabricated from $85 \mu \mathrm{m}$ raw powders) in such temperature range. Amongst the three tested Ti-6Al-4V/(TiC+TiB) composites, the one with $50 \mu \mathrm{m}$ network diameter possess the most outstanding UTS-ductility combination;

(3) Theoretical assessment of potential strengthening mechanisms reveals that the enhanced tensile strength at elevated temperatures is mainly ascribed to : (i) carbon interstitial solute strengthening; (ii) reinforce-assisted grain refinement strengthening; and (iii) extensive dispersoid strengthening, including both Orowan mechanisms and effective load transfer;

(4) Fractographic and failure analyses suggest that at relatively lower temperatures reinforce/matrix interface contribute to the majority of crack propagation pathways owing to the localized strain incompatibility which causes brittle-like fracture; while at higher temperatures, matrix tearing and reinforcer cut-through mechanisms occur, leading to the observed fracture elongation enhancement.

\section{Acknowledgements}

This work was financially supported by National Key R\&D Program of China (No. 2017YFB0703100), National Natural Science Foundation of China under the grant numbers of 51822103, 51671068, and 51731009, and Fundamental Research Funds for the Central Universities (No. HIT.BRETIV.201902). Shaolou Wei would like to 
express his gratitude to Dr. Shaoshi Rui from Tsinghua University for stimulating discussion on fracture mechanics.

\section{References}

T.M. Pollock: Nat. Mater., 2016, vol. 15, pp. 809-15.

A.L. Pilchak, G.A. Sargent, and S.L. Semiatin: Metall. Mater. Trans. A Phys. Metall. Mater. Sci., 2018, vol. 49, pp. 908-19.

R.J. Bennett, R. Krakow, A.S. Eggeman, C.N. Jones, H. Murakami, and C.M.F. Rae: Acta Mater., 2015, vol. 92, pp. 278-89.

A.M. Birt, V.K. Champagne, R.D. Sisson, and D. Apelian: Metall. Mater. Trans. A Phys. Metall. Mater. Sci., 2017 , vol. 48, pp. 1931-43.

S.L. Wei, L.J. Huang, X.T. Li, Q. An, and L. Geng: J. Alloys Compd., 2018, vol. 752, pp. 164-78.

D.A. Brice, P. Samimi, I. Ghamarian, Y. Liu, R.M. Brice, R.F. Reidy, J.D. Cotton, M.J. Kaufman, and P.C. Collins: Corros. Sci., 2016, vol. 112, pp. 338-46.

Y. Niu, H. Hou, M. Li, and Z. Li: Mater. Sci. Eng. A, 2008, vol. 492, pp. 24-8.

P.L. Narayana, S.W. Kim, J.K. Hong, N.S. Reddy, and J.T. Yeom: Mater. Sci. Eng. A, 2018, vol. 718, pp. $287-91$.

I. V. Okulov, M. Bönisch, A. V. Okulov, A.S. Volegov, H. Attar, S. Ehtemam-Haghighi, M. Calin, Z. Wang, A. Hohenwarter, I. Kaban, K.G. Prashanth, and J. Eckert: Mater. Sci. Eng. A, 2018, vol. 733, pp. 80-6.

L.Y. Du, L. Wang, W. Zhai, L. Hu, J.M. Liu, and B. Wei: Mater. Des., 2018, vol. 160, pp. 48-57.

T.M. Butler, C.A. Brice, W.A. Tayon, S.L. Semiatin, and A.L. Pilchak: Metall. Mater. Trans. A Phys. Metall. Mater. Sci., 2017, vol. 48, pp. 4441-6.

I.N. Maliutina, H. Si-Mohand, R. Piolet, F. Missemer, A.I. Popelyukh, N.S. Belousova, and P. Bertrand: Metall. Mater. Trans. A Phys. Metall. Mater. Sci., 2016, vol. 47, pp. 378-87.

I. Gurrappa and A.K. Gogia: Surf. Coatings Technol., 2001, vol. 139, pp. 216-21. 
K.B. Panda and K.S.R. Chandran: Metall. Mater. Trans. A Phys. Metall. Mater. Sci., 2003, vol. 34, pp. $1371-85$.

T.W. Clyne and P.J. Withers: An Introduction to Metal Matrix Composites, 1995.

J.C. Hanan, G.A. Swift, E. Üstündag, I.J. Beyerlein, J.D. Almer, U. Lienert, and D.R. Haeffner: Metall. Mater. Trans. A Phys. Metall. Mater. Sci., 2002, vol. 33, pp. 3839-45.

K.M. Rahman, V.A. Vorontsov, S.M. Flitcroft, and D. Dye: Adv. Eng. Mater., 2017, vol. 19, pp. 3-8.

S. Mahesh and A. Mishra: Eng. Fract. Mech., 2018, vol. 194, pp. 86-104.

Y. Jiao, L. Huang, and L. Geng: J. Alloys Compd., 2018, vol. 767, pp. 1196-215.

C. Leyens and M. Peters: Titanium and Titanium Alloys, 2003.

F. Appel, J.D.H. Paul, and M. Oehering: Gamma Titanium Aluminide Alloys: Science and Technology, 2011.

Y. Li, L. Xiao, W. Lu, J. Qin, and D. Zhang: Mater. Sci. Eng. A, 2008, vol. 488, pp. 415-9.

B.J. Choi, I.Y. Kim, Y.Z. Lee, and Y.J. Kim: Wear, 2014, vol. 318, pp. 68-77.

J.P. Qu, C.J. Zhang, J.C. Han, S.Z. Zhang, F. Yang, and Y.Y. Chen: Vacuum, 2017, vol. 144, pp. $203-6$.

L.J. Huang, L. Geng, A.B. Li, F.Y. Yang, and H.X. Peng: Scr. Mater., 2009, vol. 60, pp. 996-9.

S. Wang, L.J. Huang, L. Geng, F. Scarpa, Y. Jiao, and H.X. Peng: Sci. Rep., 2017, vol. 7, pp. 1-13.

Y. Jiao, L.J. Huang, S.L. Wei, L. Geng, M.F. Qian, and S. Yue: Corros. Sci., 2018, vol. 140, pp. 223-30.

H. Rastegari and S.M. Abbasi: Mater. Sci. Eng. A, 2013, vol. 564, pp. 473-7.

Z. Yang, H. Huan, C. Jiang, W. Li, X. Liu, and S. Lyu: Thin Solid Films, 2011, vol. 519, pp. 4804-8.

L. Xie, Q. Zhou, X. Jin, Z. Wang, C. Jiang, W. Lu, J. Wang, and Q. Jane Wang: Int. J. Fatigue, 2014, vol. 66, pp. $127-37$.

S.J.. Kang: Sintering: Densification, Grain Growth, and Microstructure, 2005.

R.W. Balluffi, S.M. Allen, and W.C. Carter: Kinetics of Materials, 2005.

L.J. Huang, L. Geng, H.X. Peng, and B. Kaveendran: Mater. Sci. Eng. A, 2012, vol. 534, pp. 688-92.

S. Balachandran, S. Kumar, and D. Banerjee: Acta Mater., 2017, vol. 131, pp. 423-34.

S.L. Wei, L.J. Huang, J. Chang, W. Zhai, S.J. Yang, and L. Geng: Mater. Lett., 2016, vol. 175, pp. $291-5$.

E. Nes, N. Ryum, and O. Hunderi: Acta Mater., 1985, vol. 33, pp. 11-22.

A. Takeuchi and A. Inoue: Mater. Trans., 2005, vol. 45, pp. 2817-29.

R.L. Fleischer: Acta Metall., 1962, vol. 10, pp. 835-42.

Hall E. O.: Proc. Phys. Soc. Sect. B, 1951, vol. 64, p. 747. 
R.L. Jones and H. Conrad: Trans. AIME., 1969, vol. 245, pp. 779-89.

K.Y. Wang, T.D. Shen, M.X. Quan, and W.D. Wei: J. Mater. Sci. Lett., 1993, vol. 12, pp. 1818-20.

A.A. Popov, I.Y. Pyshmintsev, S.L. Demakov, A.G. Illarionov, T.C. Lowe, A. V. Sergeyeva, and R.Z. Valiev: Scr. Mater., 1997, vol. 37, pp. 1089-94.

R.J. Lederich, S.M.L. Sastry, E.J. O’Neal, and B.B. Rath: Mater. Sci. Eng., 1978, vol. 33, pp. 183-8.

A. Argon: Strengthening Mechanisms in Crystal Plasticity, 2012.

M.R. Akbarpour, E. Salahi, F. Alikhani Hesari, H.S. Kim, and A. Simchi: Mater. Des., 2013, vol. 52, pp. 881-7.

A.A. Griffith: Philos. Trans. Ser. A, 1920, vol. 221, pp. 163-98.

M. Wang, Z. Yang, B. Ji, F. Zhu, L. Xiao, W. Lu, J. Qin, and D. Zhang: Mater. Sci. Eng. A, 2008, vol. 491, pp. 192-8.

C.J. Zhang, F.T. Kong, S.L. Xiao, E.T. Zhao, L.J. Xu, and Y.Y. Chen: Mater. Sci. Eng. A, 2012, vol. 548, pp. 152-60.

\section{List of Figures and Tables:}

Figure 1 | Specific strength versus service temperature for typical structural materials (data excerpted from $\left.r e f .{ }^{[24,25]}\right)$.

Figure 2 | SEM micrographs for powder morphology: (a) graphite; (b) Ti-6Al-4V; (c) TiB ${ }_{2}$; (d) mixed powder after 5 $h$ low-energy ball-milling (inset: higher magnification image of powder surface).

Figure 3 | Thermodynamic and kinetic calculation results: (a) equilibrium phase constitution with respect to temperature; (b) relative density change versus time at an applied pressure of $25 \mathrm{MPa}$.

Figure 4| SEM micrographs for Ti-6Al-4V/(TiC+TiB) composites sintered at various temperatures under $25 \mathrm{MPa}$ for 60 min: (a1) and (a2) $1000^{\circ} \mathrm{C}$; (b1) and (b2) $1100^{\circ} \mathrm{C}$; (c1) and (c2) $1200^{\circ} \mathrm{C}$.

Figure 5 | Phase constitution and microstructure of Ti-6Al-4V/(TiC+TiB) composites fabricated under optimized processing conditions: (a) mechanistic schematics of TiB and TiC formation; (b) XRD patterns for composites and Ti-6Al-4V alloy; (c) SEM image of reinforcer morphology; (d) EDS point scan of selected spots denoted in as "point $A$ " and "point $B$ " in (c). 
Figure 6| Meso-scale elemental distribution characteristics: (a) SEM micrograph of the selected area of interest; (b)-(f) Ti, Al, V, C, and B mappings.

Figure 7| HRTEM characterization of reinforcer/matrix interface: (a) $\alpha$-Ti/TiB interface; (b) $\alpha$-Ti/TiC interface; (a1) and (a2) FFT analyses of selected area in (a); (b1) and (b2) FFT analyses of selected area in (b).

Figure $8 \mid$ High-temperature tensile properties of Ti-6Al-4V/(TiC+TiB) composites with various network diameters: (a) $500^{\circ} \mathrm{C}$; (b) $550^{\circ} \mathrm{C}$; (c) $600^{\circ} \mathrm{C}$; and (d) $650^{\circ} \mathrm{C}$.

Figure 9 | Tensile property comparison amongst Ti-6Al-4V/(TiC+TiB) composites, Ti-6Al-4V/TiB composites (network size: $110 \mu \mathrm{m})^{[37]}$, and monolithic Ti-6Al-4V alloys (fabricated from $85 \mu \mathrm{m}$ raw powders) ${ }^{[15]}$ at elevated temperatures: (a) ultimate tensile strength; (b) fracture elongation.

Figure 10 | OM images of $\alpha$-grain size in: (a) monolithic Ti-6Al-4V alloys; (b)-(d) Ti-6Al-4V/(TiC+TiB) composites with 50,100, and $140 \mu \mathrm{m}$ network diameter.

Figure 11 | Theoretical estimation of Hall-Petch strengthening in Ti-6Al-4V/(TiC+TiB) composites, Ti-6Al-4V/TiB composites (network size $110 \mu \mathrm{m}$ ), and monolithic Ti-6Al-4V alloys (fabricated form $85 \mu \mathrm{m}$ raw powders)

Figure 12 | Representative fracture morphology of Ti-6Al-4V/(TiC+TiB) composites at various temperatures: (a) fracture surface at $550{ }^{\circ} \mathrm{C} ;\left(\right.$ b) and (c) fracture cross-sections at 600 and $650{ }^{\circ} \mathrm{C}$; (d) fracture surface at $650^{\circ} \mathrm{C} ;(\mathrm{e})$ higher magnification image showing matrix tearing cracking.

Figure 13 | Fracture mechanisms at elevated temperatures: (a) phenomenological schematics of energy barrier for cracking propagation along each pathway; (b) schematics of potential crack propagation modules.

Figure 14 | Comparison amongst the present results and similar cast composites in the literature: solid symbols represent present study, while haloed symbols denote data excerpted from the reference. Different colors (dark gray, blue, green, orange, and red) are utilized to highlight temperature and the arrows indicate increasing temperature.

Table 1 | Chemical compositions of Ti-6Al-4V alloy powders used for composites fabrication 
Table 2 | Physical parameters adopted for densification kinetics calculation

Table 3 | Summary of average $\alpha$-grain size within different materials

Table $4 \mid$ Lattice parameters of $\alpha-T i$ in Ti-6Al-4V alloy and Ti-6Al-4V/(TiC+TiB) composites at ambient temperature 